IZA DP No. 5164

Do Natural Disasters Affect Human Capital? An Assessment Based on Existing Empirical Evidence

Javier Baez

Alejandro de la Fuente

Indhira Santos

September 2010 


\title{
Do Natural Disasters Affect Human Capital? An Assessment Based on Existing Empirical Evidence
}

\author{
Javier Baez \\ World Bank and IZA
}

\author{
Alejandro de la Fuente \\ World Bank
}

Indhira Santos

Bruegel

\section{Discussion Paper No. 5164 \\ September 2010}

\author{
IZA \\ P.O. Box 7240 \\ 53072 Bonn \\ Germany \\ Phone: +49-228-3894-0 \\ Fax: +49-228-3894-180 \\ E-mail: iza@iza.org
}

\begin{abstract}
Any opinions expressed here are those of the author(s) and not those of IZA. Research published in this series may include views on policy, but the institute itself takes no institutional policy positions.

The Institute for the Study of Labor (IZA) in Bonn is a local and virtual international research center and a place of communication between science, politics and business. IZA is an independent nonprofit organization supported by Deutsche Post Foundation. The center is associated with the University of Bonn and offers a stimulating research environment through its international network, workshops and conferences, data service, project support, research visits and doctoral program. IZA engages in (i) original and internationally competitive research in all fields of labor economics, (ii) development of policy concepts, and (iii) dissemination of research results and concepts to the interested public.
\end{abstract}

IZA Discussion Papers often represent preliminary work and are circulated to encourage discussion. Citation of such a paper should account for its provisional character. A revised version may be available directly from the author. 


\section{ABSTRACT \\ Do Natural Disasters Affect Human Capital? An Assessment Based on Existing Empirical Evidence*}

The last few years have seen a notable increase in the number of studies investigating the causes and effects of natural disasters in many dimensions. This paper seeks to review and assess available empirical evidence on the ex-post microeconomic effects of natural disasters on the accumulation of human capital, focusing on consumption, nutrition, education and health, including mental health. Three major findings come forward from this work. First, disasters appear to bring substantial damages to human capital, including death and destruction, and produce deleterious consequences on nutrition, education, health and many income-generating processes. Furthermore, some of these detrimental effects are both large and long-lasting. Second, there is a large degree of heterogeneity in the size - but not much in the direction - of the impacts on different socioeconomic groups. Yet, an empirical regularity across natural hazards is that the poorest carry the heaviest burden of the effects of disasters across different determinants and outcomes of human capital. Finally, although the occurrence of natural hazards is mostly out of control of authorities, there still is a significant room for policy action to minimize their impacts on the accumulation of human capital. We highlight the importance of flexible safety nets as well as the double critical role of accurate and reliable information to monitor risks and vulnerabilities, and identify the impacts and responses of households once they are hit by a disaster. The paper also lays out existing knowledge gaps, particularly in regard to the need of improving our understanding of the impacts of disasters on health outcomes, the mechanisms of transmission and the persistence of the effects in the long-run.

JEL Classification: $\quad$ 100, O10, 015

Keywords: natural disasters, human capital accumulation

Corresponding author:

Javier Baez

The World Bank

1818 H Street, NW

MSC 9-006A

Washington, DC 20433

USA

E-mail: jbaez@worldbank.org

\footnotetext{
* We thank Apurva Sanghi and other participants at the Global Facility for Disasters Risk Reduction and Recovery Seminar, World Bank, held on January 29, 2009 in Washington, D.C., for their helpful comments. The views and conclusions do not necessarily represent the position of Bruegel, IZA, or the World Bank or its member countries. Any remaining errors are our own.
} 


\section{Introduction}

The last few years have seen a notable increase in the number and impacts of natural disasters, either because they are now better measured, affect more people or in fact occur more frequently and are more severe - or probably due to the combination of all or part of them. Consequently, there has been an explosion of studies investigating both the causes and effects of natural disasters in many dimensions. Largely motivated by this, this paper seeks to assess available empirical evidence on the ex-post microeconomic effects of natural disasters on the accumulation of human capital, a key issue that justifies its importance itself for its economic, social and moral relevance. To achieve this, we conduct a critical review of the relevant literature, with an emphasis on the development economics literature, aimed to synthesize, integrate and interpret existing findings, and shed some light on remaining knowledge gaps. Since natural disasters have also taken a prominent role in the policy agenda, we provide a set of specific implications for policy that emerge from our assessment of the literature.

Many choices have determined the way this paper approaches the literature and the way the messages are presented and discussed. Firstly, considering that the concept of human capital can be very broad, this study will refer to it as the level of education and skills developed over the early stages of life until adolescence, including key inputs such as the nutritional and health status of individuals, both physical and mental. Consistent with this, the paper is organized around four dimensions closely linked to the accumulation of human capital:

incomes/consumption, nutrition, education and health, including mental health. Secondly, like in almost every field, there is substantial dispersion in the empirical rigor of existing studies across different socio-economic risks sensitive to natural disasters. Thus, we have placed a strong interest in inferring results from papers that rely on careful empirical methods and explicitly mention the themes for which is less feasible to do so. Thirdly, throughout the document we make the distinction between short- and long-term effects of natural disaster on the outcomes of interest. The depth of this distinction, however, varies across topics and is mostly driven by the availability of data and relevant studies.

For practical reasons, this paper focuses on the ex-post consequences of natural disasters on the margins noted above. Yet, uninsured risks arising from natural hazards are as important and 
can have multiple effects even before they materialize. Indeed, uninsured and unrealized risks have been shown to distort decisions and encourage adverse behaviors in a number of aspects: low-risk, low-return inputs and production methods (Dercon et al., 2006; Morduch, 1995; Rosenzweig et al., 1993; Bliss et al., 1982), lower adoption of more productive technologies (Foster et al., 1996; Eswaran et al., 1990) and sub-optimal income diversification decisions in terms of production (Dercon, 1996; Morduch, 1990; Bellon, et al., 1992) and labor supply choices (Rosenzweig et al., 1989; Kochar 1995 \& 1999 ; Townsend, 1995; Jalan et al., 1999). Furthermore, where risk environments reduce the returns on education, investments in human capital can be postponed or ceased. Even though this paper does not review this part of the literature in detail, it takes into account the multiple interactions that shape the dynamics of the effects of natural disasters on human capital when appraising the ex-post part of the process.

Three major findings come forward from this work. First, and most obviously, disasters are the antithesis of human development. They bring substantial damages, including death and destruction, and seriously jeopardize recovery of human and physical assets. But even when disaster-related mortality is absent, disasters can bring deleterious consequences on nutrition, education, health and many income-generating processes. Along this is the magnitude and persistence of the effects. Indeed, this review of the literature reveals that some of the potential detrimental effects identified can be both large and long-lasting. The flip side of the coin is that not all of the effects of natural disasters are irreversible and even some have implicit benefits. The destruction of old and inefficient physical capital, for instance schools and health clinics, offers the opportunity to replace it with newer and more efficient infrastructure.

Second, disasters do not affect people equally. There is a high degree of heterogeneity in the size - but not much in the direction - of the impacts on different socioeconomic groups. Inequalities in risk exposure and sensitivity to risk and in access to resources, opportunities and capabilities, put specific segments of the population in a disadvantaged position. Identifying general patterns in the magnitude of the impacts is not easy due to the large variety of disasters and the complexity of the interactions triggered by them. In spite of this, an incontestable empirical regularity across natural hazards is that the poorest carry the heaviest burden of the effects of disasters across different determinants and outcomes of human capital. 
Finally, although the occurrence of natural hazards is for the most part out of control of authorities, there still is a significant room for policy action to deal with their impacts or with the effects of latent risks on the accumulation of human capital. There is a varied set of policy tools that range from improving prevention and systems and risk-managements strategies ex-ante to strengthening coping (formal and informal) mechanisms both at the household, sub-national and national levels. There is not a unique set of instruments that should be preferred in all cases. Instead, their success is determined by local realities and tradeoffs. We highlight two specific areas that can complement the standard menu of interventions. First, the importance of designing scalable, flexible and well-targeted social assistance programs (e.g. conditional cash transfers, workfare programs, etc) to assist affected populations. Second, the double critical role played by accurate and reliable information to monitor risks and vulnerabilities, and identify the impacts and responses of households once they are hit by a disaster.

The paper is organized as follows. The next section presents a simple conceptual framework for the possible mechanisms through which natural disasters can have an impact on human capital. The third section is the core of this paper. It discusses the possible short- and long-term effects of natural disasters around four areas closely connected to the accumulation of human capital or the returns of it (income/consumption, nutrition, schooling and health). Section four takes stock of what researchers and policymakers can learn from the existing literature and further highlights those areas where the evidence is still weak and more research is required. Section five concludes with the policy recommendations arising from this literature review.

\section{Conceptual Framework}

Modeling the impacts of natural disasters on human capital in a comprehensive manner is quite complex. They differ greatly in their nature, intensity, channels and socio-economic consequences on populations. Doing this is out of the scope of this paper. Moreover, other studies in the literature have developed theoretical frameworks to model different pieces of the causal chain linking distinct shocks -including disasters - to proxy determinants of human capital and other dimensions of human welfare. Our approach here, instead, seeks to integrate predictions from existing models around a simple model that incorporates the behaviors of 
households to highlight the most obvious shocks and mechanisms of transmission and the plausible direction of the effects embedded in them.

We start with a basic distinction regarding the types of effects on the elements connected to the creation and use of human capital. On the one hand, there is a group of "direct effects" which are mostly related to the disruptive power of natural disasters on socio-economic systems. Examples of these effects are the loss of human lives, rise of disabilities, destruction of complementary physical capital and infrastructure (e.g. schools, health centers, roads, etc.), loss of teachers and medical personnel and the deterioration of the public health environment (e.g. development of epidemics, mental health, etc.). On the other hand, these direct impacts translate into a series of "indirect effects", which comprise macro effects (e.g. fiscal constraints, general equilibrium effects on prices and earnings) and micro, household-level effects (e.g. tighter budget constraints due to, for instance, losses of incomes and changes in other behaviors such disincentive effects to invest in human capital in the face of a high or increasing probability of disability/mortality.

While natural hazards can affect a person's human capital throughout its entire life, it is at early stages in life when any such impacts most matter if they are not properly and timely addressed. Temporary poor health and child malnutrition can have persistent effects because they tend to reverberate into the further processes of human capital accumulation, such as school performance, cognitive development and then earnings and productivity. ${ }^{1}$ For this same reason, our theoretical framework is developed bearing in mind this consideration.

The impact of natural disasters on children's future human capital stock will be realized through the channels discussed above and the choices their parents make on their behalf in the aftermath of an event. Following Baez and Santos (2007), we integrate these mechanisms using a one-period simple model that assumes full information and a unitary household. ${ }^{2}$ The utility function of the parents includes household consumption (C) and the future earnings of the

\footnotetext{
${ }^{1}$ These long-lasting effects are particularly worrying and it is therefore no coincidence that a vast portion of the literature on the impact of natural disasters on human capital is concerned with the specific burden on children.

2 This model builds on a model developed by Skoufias et al., (2001), which presents a static version. Yet, it still tries to incorporate some of the features of a dynamic framework.
} 
children (E). Parents care about their children because they will receive a fraction $\phi$ of their future earnings. Parents’ objective function is, therefore, given by:

$$
\max U=U(C, E),
$$

where $U^{\prime}(\bullet)>0$ and $U^{\prime \prime}(\bullet)<0$ for both arguments.

We combine education and health in human capital. The evolution of human capital is defined by the stocks and flows: S, which represents the stock of human capital at the beginning of the period; and $\mathrm{H}$, which is the investment in human capital during the period. We further assume that children's future earnings is defined by an additively separable function of $\mathrm{S}$ and $\mathrm{H}$, and their innate abilities and health endowment $(\chi)^{3}$ :

$$
E=\alpha(S+H)+\beta \chi
$$

where $\alpha$ and $\beta$ are the contributions of human capital and genetics, respectively.

Human capital inve stment is a function of complementary goods, $X$ (services, books, vaccines, etc.); the time the child spends in school or medical care, $t_{H}^{c}$; and the time that parents dedicate to investment in each child's quality, $t_{H}^{p}$. The marginal effects of $X, t_{H}^{c}$ and $t_{H}^{p}$ on human capital are all assumed to be positive. Similarly, human capital investment depends on a set of observed characteristics of the child, $\theta$ (including gender, age, birth order, among others); unobserved characteristics of the child, $\chi$, (health endowment or innate abilities) and finally, $\delta$, which captures parental education and community characteristics such as the availability of health centers and schools, prices, environmental factors, among others. The reduced-form function of the human capital investment in the child can then be represented as follows:

$$
H=H\left(X, t_{H}^{c}, t_{H}^{p} ; \theta, \chi, \delta\right)
$$

Expenditures have two components: household consumption of goods and services $C$ (numeraire) - excluding inputs into the production human capital, and the consumption of goods and services related to human capital, $p_{x} X N$ (where $p_{x}$ denotes the vector of prices of "human

\footnotetext{
${ }^{3}$ A different version of the model can incorporate the interactions that ake place between the accumulation of human capital and individuals innate abilities and health endowments.
} 
capital" goods and $N$ is the number of children in the household). The resources of the household include assets $(A)$ and income. There are four different sources of income: non-labor income of the household $\left(Y_{n l}\right)$, labor income of all children today $\left(W^{c}\left(T-t_{H}^{c}\right) N\right)$, labor income of the parents $\left(W^{p}\left(T-N t_{H}^{p}\right)\right)$ and a fraction of the labor income of adult children $\left(\phi N_{A} E\right)$. Labor income of each child is equal to his wage $\left(W^{c}\right)$ multiplied by the number of time units he dedicates to work (i.e. the difference between the total time endowment and the time spent in school or medical care). The labor income of the parents, similarly, is equal to their wage $\left(W^{p}\right)$ times the number of time units they dedicate to work. Therefore, the budget constraint of the household is:

$$
C+p_{x} X N=Y_{n l}+W^{c}\left(T-t_{H}^{c}\right) N+W^{p}\left(T-N t_{H}^{p}\right)+\phi N_{A} E+A
$$

Households maximize utility (1) subject to restrictions (2) - (4), by choosing the appropriate levels of consumption $(C)$, time allocated to human capital $\left(t_{H}^{c}, t_{H}^{p}\right)$, and consumption of goods and services complementary to human capital investment $(X)$. The first-order conditions at the optimum are the following:

$$
\begin{aligned}
& M R S_{C E}=\frac{U_{E}}{U_{C}}=N\left(\frac{W^{C}}{\alpha H t_{H}^{c}}-\phi\right)=M C_{t_{H}^{c}} \\
& M R S_{C E}=\frac{U_{E}}{U_{C}}=N\left(\frac{W^{p}}{\alpha H t_{H}^{p}}-\phi\right)=M C_{t_{H}^{p}} \\
& M R S_{C E}=\frac{U_{E}}{U_{C}}=N\left(\frac{P_{X}}{\alpha H_{x}}-\phi\right)=M C_{X}
\end{aligned}
$$

At the optimum, households will maximize their utility by setting the marginal cost associated with the time of the child, the time of the parents and the consumption of "human capital” goods and services all equal. ${ }^{4}$ These solutions, then, can be used to examine the behavior of households when exposed to shocks. Changes to any of these parameters, caused for instance by natural disasters, will induce changes in the household's investment in children's education and health.

\footnotetext{
${ }^{4}$ Equivalently, the marginal rate of substitution between household consumption and child quality equals the marginal cost of investing in the human capital of the child.
} 
We focus initially on the direct effects of natural disasters. Aside from death and disease, which have a clear direct negative impact on the child's human capital, the loss of complimentary goods, services, infrastructure and other resources (including, for example, the loss of teachers' and health personnel's lives) translates into higher marginal costs for the production of human capital. Disasters can also destroy assets in the form of housing, capital and inventories and, thus, reduce family budgets. This in turn can induce a decline in some or all expenditures, including food, health and education - assuming these three are normal goods.

As noted above, these direct impacts of disasters set off other indirect mechanisms. We center our attention on three in particular. First, there is an indirect effect on households' incomes but the direction of such change is unknown from a theoretical standpoint. ${ }^{5}$ Most existing evidence, however, points to a fall in the aftermath of a disaster. If so, this would lead to changes in households' expenditures for credit constrained households - of similar nature to those triggered by losses in assets - including a fall in investments in children's schooling and health. Indeed, these income effects seem to be significant in many developing countries (Santos, 2007).

Second, it is not clear a priori if in the aftermath of a natural disaster the marginal cost of parental time increases or decreases. On the one hand, one can argue that the wave of destruction leaves many parents without employment and/or with less recreational activities without their children (as in the case of recessions and discussed in Ferreira and Schady, 2008). On the other hand, reconstruction activities inside and outside the household, may leave parents - and children - with less time available to spend in the "production" of human capital, increasing the marginal cost of this key input.

The third indirect channel arises from the general macroeconomic effects of natural disasters and their likely impact on wages and prices. Again, the theory and the empirical evidence do not provide a unique prediction on regard to the direction of the effects at the microlevel. It is in fact straightforward to think of various situations in which wages and prices vary in different directions. Furthermore, change in wages and prices are accompanied by income and

\footnotetext{
${ }^{5}$ Although the empirical evidence seems to point at significant falls in income in the aftermath of a natural disaster due to loss of crops, jobs or business (Baez and Santos, 2009), it is possible that this fall is totally or partially offset by the boost to income in the aftermath of a disasters. For instance, households can benefit from reconstruction activities or direct transfers. Net producers can also benefit if prices of their goods and services go up after a disaster.
} 
substitution effects that have distinct predictions for the impact on the child's human capital - in particular, education and child labor. If one assumes that wages fall in the aftermath of a disaster, the latter would predict an increase in children's human capital since the opportunity cost of human capital, the wage, is now lower. However, as the income effect goes in the opposite direction, formally, the net change would be unknown.

This simple framework illustrates that the effect of natural disasters on human capital are theoretically ambiguous. Even though the direct effects can accurately predict a negative impact on children's human capital, the indirect effects as a whole can either reinforce or diminish such deterioration. This ambiguity is further compounded by the positive and negative effects induced by other factors such as the exposure to disaster risk, risk management and coping strategies during hardship, other behaviors, and the dynamics of the impacts. Consequently, the net extent of the effects, and even their direction, can be expected to vary across households, types of shocks, environment and time. In those situations where budgetary constraints tighten and credit and insurance markets are imperfect, the impact of a natural disaster on children's human capital outcome should be larger. It is because this budgetary mechanism is so crucial - especially for poor households - that our review of the literature starts with empirical evidence that exists on the impact of natural disasters on households' consumption.

\section{The Consequences of Natural Disasters on Human Capital}

We have just argued that theory alone does not answer the question of whether natural disasters have consequences on the creation and use human capital. Many papers have attempted to fill this gap empirically, investigating several margins of interest with different methods and datasets. Substantial advances have been achieved in terms of identifying and quantifying the impacts of disasters as well as analyzing the complex interactions at stake. This section seeks to review and synthesize existing findings at the household level in order to highlight empirical regularities and detect remaining knowledge gaps. The order followed in this overview is determined by the likely chronological chain of effects triggered by a natural disaster. First, it focuses on the impacts on consumption, the standard measure of household welfare. Next, largely motivated by the inability to fully smooth consumption after a shock, we move to other 
dimensions of welfare that are both responsive to disasters and proximate determinants of human capital accumulation such as nutrition, schooling and health, including mental health.

\section{Effects of Disasters on Consumption Volatility}

The most observable and direct impact of natural disasters is the loss of human lives, the rise in physical disabilities and the damage or destruction of public infrastructure, private physical and productive capital. In urban areas, livelihood damages are mainly reflected in housing, which in many contexts constitutes also a source of livelihood and not just welfare. Other losses may occur on infrastructure (water, sanitation, electricity) or social facilities (schools, health centers). In rural areas, natural disasters may result in the loss of crops and livestock, and destruction of housing and infrastructure as in urban areas.

The loss -or interrupted access to income-generating assets occasioned by climatic and geological events alike can lead to short-term drops in income. And tighter budgets have the potential to lessen consumption. For instance, Baez and Santos (2008) exploit variation in the intensity of two earthquakes that struck El Salvador in 2001 to find that both events are associated with a reduction in income per capita (one third of the pre-shock average level) among households in the upper half of the ground shaking distribution. Likewise, the drought that hit Burkina Faso between 1984 and 1985 increased household consumption poverty in the Sahelian (2 to 19\%) and Sudanian (12 to 15\%) zones of the country (Kazianga and Udry, 2006; Fafchamps, Udry and Czukas, 1998; Reardon and Taylor, 1996).

To counter these effects on consumption, and in the absence or limited access to formal credit and insurance markets that characterizes many parts of the developing world, households resort to self-help and mutual insurance mechanisms. Asset-based self-insurance strategies include savings in the form of stored grain or small and large livestock in rural areas, or jewelry and durables in urban areas for potential sales. Informal insurance arrangements comprise local borrowing schemes with friends and neighbors as well as private transfers that originate from relatives. 
However, there is widespread evidence that these coping mechanisms do not to provide households with full insurance against disaster risk. A large number of studies find after regressing changes in the growth rate of household consumption on some measure of aggregate risk (an indicator of rainfall variability or the growth rate of total community income - which can be thought as the summation of all risks affecting the village, including disasters), that the variation in the aggregate source or risk accounts for a significant proportion of variation in expenditure (for some reviews see Alderman and Paxson, 1994; Baez and Mason, 2008; Morduch, 1995, 1999; Dercon, 2002; Townsend, 1995). In other words, the consumption streams of households are largely susceptible to disasters, despite the reliance of households on various risk-management and coping mechanisms. ${ }^{6}$

Instruments to save and savings themselves are often precarious in disaster situations because of the high covariance between income sources and asset values, especially in rural areas. This means that consumption smoothing through asset sales may be incomplete because other households simultaneously seek to sell their assets, driving down prices. In urban areas inkind savings are usually at direct risk of extinction during natural hazards or are also insufficient to deal with their covariate nature.

A well-known example of the limitations of asset-based strategies relates to the famine in Ethiopia in 1984-85, when households in Northern Wollo in Ethiopia used their standard smoothing device - selling small and larger livestock - to cope with the drought, but then livestock prices collapsed due to oversupply and lack of demand, in the face of high grain prices (Dercon, 2008). In another commonly cited study on farm households in Burkina Faso, Fafchamps, Udry and Czukas (1998) found that livestock sales only compensated for twenty to thirty percent of crop income shortfalls induced by a drought in 1984-85. Using the same data, but this time exploiting also consumption data, Kazianga and Udry (2006) tested the degree of consumption smoothing for the same group of households and again with respect to aggregate income shocks. They discovered that income variations accounted for a significant proportion of variation in consumption and only a quarter of the income variability was smoothed via stored grains.

\footnotetext{
${ }^{6}$ Most studies under this ('consumption smoothing' and 'risk-sharing') literature infer that existing risk-mitigating mechanisms are imperfect since they do not allow households to smooth consumption fully, but few studies test these mechanisms individually or directly.
} 
As for group-based risk sharing mechanisms, the standard argument for explaining their inability to provide full insurance against natural disasters is that these events affect many households simultaneously wiping out the entire network's resources and thus making it difficult to share risk. For instance, being a member of a rural financial institution where deposits are from community members engaged in agricultural activities may be of little help for lending purposes to face any flood or harvest failure because most probably those deposits will be withdrawn all at once during the hardship (Skoufias, 2003) ${ }^{7}$.

The relevance of all this findings for this paper is that uninsured disaster risk (resulting from imperfections of formal and informal credit and insurance markets) can have substantial and persistent impacts on human capital through the inability to protect consumption expenditures on food, health or education. Alternatively, in an attempt to smooth consumption, households can resort to coping strategies which lead to persistent negative effects on human capital, such as cutting back food consumption below adequate levels or dropping children out of school (Jacoby and Skoufias, 1997; Kochar, 1995; Rose, 2001; Moser, 1998).

\section{Impacts on Consumption in the Long-Run}

While coping with disasters, households can also dispose of productive assets, such as livestock and land, which could be the basis of longer term growth. There are numerous examples showing that it takes a significant amount of time for affected households to bring their assets and consumption back to at least pre-disaster levels. And this need to regain or safeguard a bare minimum of consumption may shift household investments away from those in human capital. For instance, using panel data for Ethiopia Dercon (2004) observed that it took on average ten years for asset poor households exposed to the 1984-85 famine to recover their initial livestock holdings. Moreover, the most severely damaged households displayed 4 to 16 lower percentage points in consumption growth during the mid 1990's relative to others less affected (Dercon, 2004).

\footnotetext{
7 Skoufias, Emmanuel. "Economic Crises and Natural Disasters: Coping Strategies and Policy Implications." (2003). World Development, 31(7), pp. 1087-102.
} 
For a similar group of rural households a series of shocks between 1999 and 2004, many related to weather events, led to a loss of productive assets of up to 40 percent for the most affected (Dercon et al., 2007). More importantly, experiencing a drought between 1999 and 2002 led to about 14\% less consumption per capita by 2004 compared to that of the unaffected counterparts (Dercon, Hoddinott and Woldehana, 2005). Little and colleagues (2007) observed a similar persistence of drought on consumption while investigating the impact of the 1999-2000 drought in South Wollo, Ethiopia. About 95 percent of the households who became poor after the drought remained in such stage after six years -and was estimated that it would take them 810 years to reach the poverty threshold (Little et al., 2007). Even farmers that suffered droughtinduced crop shocks in Tanzania between 1991 and 1995 have undergone similar consumption experiences to those of their Ethiopian counterparts. Crop failures were associated with consumption growth losses for their households of point estimates between $17 \%$ to $40 \%$ more than ten years later, in 2004 (Beegle, et al. 2006).

The persistence of disaster effects on consumption and asset recovery has also been observed in non-African contexts. Evidence examining the long-term consequences of droughts on Brazilian labor markets hints at similar drops in rural earnings -and probably in consumption- of affected individuals even 10 years after the occurrence of the shocks (Mueller and Osgood, 2007b). Likewise, data from Honduras and El Salvador seem to confirm that households not only reduce their consumption and deplete their assets in the wake of natural disasters but also have limited ability to rebuild them (Baez, et al., 2008; Carter, et al., 2004; Rodriguez-Meza, 2003).

In short, in the face of natural disasters, households are able to achieve some level of protection through self-insurance and a wide variety of risk-sharing arrangements. However, the risk originated from hazards is not eliminated entirely and so the residual risk can have substantial impacts on household welfare, in particular in expenditures and investments in nutrition, health and education. The slow recovery of lost or sold assets after disasters could hinder long-term consumption growth. This could also compromise the accumulation of human capital in the medium to long-run as well. If households find difficulties to reestablish their livelihoods to pre-shock levels the priorities for making or sustaining investments in this type of assets could well get diverted or postponed indefinitely. 


\section{Effects of Disasters on School Attendance and Progression}

As presented in the conceptual framework, the theoretical impact of natural disasters on schooling and educational attainment is ambiguous due the varying nature of the effects involved. On the one hand, the destruction of education-related infrastructure -such as schools and complementary installations and resources - such as roads and teachers - can lead to a worsening of learning conditions and, if infrastructure is permanently damaged and not restored or if children once outside of school do not return, a direct loss of human capital. Similarly, if natural disasters worsen the economic situation of households and these are limited in their access to credit, insurance or other coping mechanisms, taking children out of school may be used to reduce the burden - when school costs are relatively high - or to increase household income by putting them to work. On the other hand, if a natural disaster changes the opportunity cost of sending children to school, through market wages for example, the direction of the overall effect is unclear.

Disentangling all these mechanisms is, of course, difficult to do empirically. But, in terms of the net effects of natural disasters on education, there is mounting evidence that the impact can be largely negative and, according to some of the existing studies, long-lasting. First, in terms of the direct effects, through the impact on infrastructure, natural shocks - in particular serious and aggregate events - have the potential to render unusable critical educational centers and related infrastructure (Annex 1). In Mozambique, for instance, the World Bank funded the construction of 487 schools over 20 years, but floods in 2000 destroyed more than 500 schools. Schools bear a central role as repositories and creators of educational human capital. They create positive externalities for society inculcating skills, attitudes and values that will be valuable for people during normal times, but also to overcome hardship sometimes (as education is a portable asset). In fact, the centrality of schools to society goes beyond the formation of human capital. When schools are destroyed by a disaster, their reconstruction and the return of children can be one of the most effective ways to demonstrate a return to normalcy to the local population and to help the government rebuild the social contract (UNDP, 2008). 
This severe damage to physical infrastructure, moreover, can also have long-term adverse effects on children's educational attainment, though this remains less well-documented. When instruction time is lost, quality of education may drop. For instance, an examination into the determinants of completed grades of schooling amongst adults born in four villages in eastern Guatemala found that the 1976 earthquake in that country had a negative impact on the number of grades attained (Stein et al., 2003).

When there are no plans for alternative teaching locations and students are denied continuous schooling, many will never be able to catch up and could drop out permanently. Also, when educational records are missing, students may fail to matriculate and go on to further education. Schools damaged beyond repair or unsafe require a level of reinvestment many times higher than the initial small incremental cost of building safely. Loss of income, housing, and delays in matriculation make it challenging for families to support children continuing their education (UNISDR, 2008).

But even with no or limited infrastructure damage, latent hazard risks and natural disasters can indirectly harm educational attainment. In fact, empirical studies have shown that households very affected by a natural shock, when left with tighter budgets, tend to cut back on basic investments in education, health and productive physical capital. A case in point is the decision to whether enroll children in school. For instance, enrollment rates declined by approximately 20 percent in regions in Ivory Coast that were hit by extreme changes between 1986 and 19987 relative to non-shock regions (Jensen, 2000). Following a similar difference in difference strategy, Jacoby and Skoufias (1997) find that school enrollments in rural areas of India were negatively affected by rainfall; a ten percent decline in agricultural income across agricultural seasons leads to a fall in school attendance of about five days. In the same way, the consequences of excessive rainfall due to Hurricane Mitch were found to reduce school retention and progression in Nicaragua (Ureta, 2005).

Aside from storms and rain variation, other extreme natural phenomena have also produced similar impacts. For example, school attendance fell by almost 7\% among those households more heavily hit by the two strong earthquakes that affected El Salvador in 2001 (Santos, 2007). 
A common feature among most of these studies is that their strategies yield reduced-form parameters of the effects of natural disasters on school attainment. Even though they are still very informative, these estimates by definition do not disentangle the factors that explain the worsening in educational outcomes. A possible interpretation of some of these findings is that these impacts can be largely driven by the underlying effects of shocks (e.g. droughts) on nutrition rather than on parents' decision to withdraw children from school. Yet, looking at other behavioral responses such as changes in the use of children's time can help gauge the effects of disasters beyond nutrition and morbidity.

The most evident of these effects is the change in the incidence of child labor in the aftermath of natural disasters. A considerable number of papers shows that disasters, economic downturns, idiosyncratic shocks and risky environments are strongly correlated with a larger workforce (including children) and more hours devoted to steady off-farm activities at the expense of lower wages (e.g. Rosenzweig and Stark (1989) and Kochar (1995, 1999) for India; Townsend (1995) for Thailand, Jalan and Ravallion, 1999 for China; Cunningham (2001) for Mexico; Vakis, Kruger and Mason (2004) and Santos (2007) for El Salvador; Baez and Santos (2007) for Nicaragua).

Santos (2007), for instance, finds that children in households most affected by the 2001 earthquakes in El Salvador were almost three times more likely to work (from 6.5\% to 16.5\%) after the shock. There was also a substantial increase in the intensive margin of their labor supply of about 32 hours per week. Child labor also increased significantly in Nicaragua as a consequence of Hurricane Mitch (Baez, et al., 2007). Similarly, a recent analysis of rural households in Central Mexico also shows that droughts have large effects in taking children out of school and in inducing them to increase their work participation (de Janvry et al., 2006).

There is also related evidence on this matter under a different setting and type of shock. In northern Tanzania, for example, child labor and chore hours are more prevalent at times when households deal with rainfall shocks and unexpected crop losses due to pests and fire compared to control households (Beegle, Dehejia and Gati, 2003). Furthermore, more recent research using the same Tanzanian dataset suggests that drawing upon the labor of children after shocks to income -including natural disasters- in fact comes at a cost in terms of human capital. In the 
particular case of boys, a 5.7 hours increase in labor reduces their school attainment by one year and increases the likelihood of marrying young by 16\%. Even for those who stay in agriculture the sector that employs most of the children, child labor causes a 3\% reduction on their marginal productivity (Beegle, Dehejia, Gatti, Krutikova, 2008). But perhaps more worrisome still is that parental investments in children that appear to be temporary adjustments to difficult times become permanent shifts. Sadoulet, Finan, de Janvry and Vakis (2004) have found that children withdrawn from school during shocks are about 30 percent less likely to continue studying compared to children who stay in school. Similarly, the study of the 1982-84 drought impact in rural Zimbabwe found that stunting in children aged 12-24 months led to delays in school enrolment (3.7 months) and reduction in grade completion (0.4 grades) 13 to 16 years after the droughts (Alderman, et.al, 2006).

In short, the existing literature on natural disasters shows that these events can have an important detrimental effect on the education stock of a country, by affecting complementary infrastructure to education, parents' incentives to send children to get educated and/or increasing the opportunity cost of going to school. Moreover, the literature on human capital and shocks further stresses that educational achievement is highly path-dependent, i.e. a child that drops out of school is less likely to come back and, if he/she does, they accumulated years of school fall. Moreover, there are important feedback effects between the different dimensions of human capital. The empirical work to date offers solid findings linking nutritional deficiencies resulting from natural disasters with reduced schooling and education (next section). All, in all, directly and indirectly, natural disasters represent a threat to educational achievement, future productivity and welfare.

\section{Effects of Disasters on Nutrition}

Natural disasters can be particularly damaging for nutritional outcomes if, in addition to their income effect in an environment of imperfect credit and insurance markets (in this case, lower income leading to lower consumption, including food), they directly affect food availability or increase the relative price of food. In this context, families close to subsistence levels, exposed to severe natural hazards and with precarious risk management and coping strategies, are in danger suffering hunger and possibly malnutrition. This distinction is relevant. 
Malnutrition, unlike hunger, is a life process that can affect productivity and resources devoted to health over a lifetime (Alderman et al., 2009).

Existing micro-level evidence confirms the strong links between the occurrence of natural disasters and the increase in the incidence of malnutrition afterwards. Cases in point are droughts triggering massive hungers, particularly in sub-Saharan Africa. The impacts vary in intensity but are generalized to all groups of people and start at very early stages of life. In rural Ethiopia, for example, children between 6 and 24 months at the onset of a drought experienced about $0.9 \mathrm{~cm}$ less growth over a six-month period between 1995 and 1996 in communities where half the crop area was damaged compared with those without crop damage (Yamano, Alderman and Christiaensen, 2005). Similar impacts have been documented for Kenya, where children born during the start of a drought were 36 percent more likely to be undernourished (Cord, et al., 2008).

Excessive precipitation is also associated with signs of malnutrition among the most vulnerable. Foster (1995), for instance, examined the consequences of the destructive floods that took place in Bangladesh in 1988. His study shows that children from landless households in affected areas experienced a significant worsening of their nutritional status, which the author attributes in part to credit market imperfections. The incidence of infant malnutrition also increased more than three times among the households most exposed to intense rainfall during Hurricane Mitch in Nicaragua in late 1998 (Baez and Santos, 2007). Rain variation, more generally, is also associated with worse nutritional outcomes. Data from Ivory Coast indicates that the prevalence of malnutrition among children increased by 3-4 percentage points in those parts of the country more exposed to both positive and negative rainfall shocks between 1986 and 1987 (Jensen, 2000).

Although the effects appear more prevalent among young children, some studies have uncovered detrimental consequences for adults. Hoddinott and Kinsey (2001) observed changes in the physiological condition of women in villages affected by the 1994-1995 droughts in Zimbabwe. A reduction of 10 percent from the historical level of rainfall was associated with a 1.15\% drop in women's body mass index, with the more detrimental effects found for women residing in the poorest households. Along the same lines, Dercon and Krishnan (2000) find drops 
of about 0.9 per cent in the body mass index of adults in households with low landholdings over a short horizon due to poor rainfall using panel rural Ethiopian data.

Accurate and timely policy interventions during natural disasters could protect the nutritional status of children, especially in early childhood. According to the study by Yamano and colleagues in Ethiopia, in the absence of food aid children growth reduced 1.8 percent after a $10 \%$ increase in crop damage. But there is also the possibility that even if this type of interventions not takes place, the effects over the health and nutritional status of children may fade away over time. That is, children may recover lost nutrition originated by the impact of natural disasters and return to their personal growth curve through 'natural' adjustment mechanisms.

Full catching up from lost height growth has been found in rural India and Philippines after controlling for the endogeneity of past anthropometric levels (Behrman, Deolalikar and Lavy, 1995). However, these results have been objected on the basis that they mix children above 3 years old with children below 3 for whom catch-up growth might not be expected (Hoddinott and Kinsey, 2001).

Other studies focusing on weight, - a rather short-term measure of nutritional status - as opposed to height, have produced evidence of catching up. In a study of weight gain among children in Bangladesh over a three-month period following the 1988 floods, children of less weight in the immediate post-flood period tend to gain more weight over the subsequent period (Foster, 1995). However, this documented catching-up in nutritional outcomes was conditional on households' wealth and access to credit. Children in better-off households or with better access to credit markets grew faster than those children residing in landless households, possibly as a result of living in households with better means to smooth their consumption and to provide them with better health care in case of sickness.

A decade later, the 1998 floods in Bangladesh caused many preschool children to lose weight. This situation was brought about by a combination of factors, including reduced access to food; increased difficulties of providing proper care for children that came with disruptions in home life; and nutrient losses due to their greater exposure to infections. However, 15 months 
after the flood, most children appeared to regain the same nutritional status they had a few months after the flood (in November 1998). Unfortunately, within the flood-exposed households ${ }^{8}$, the percentage of stunted children for those in the bottom 40 percentile of the consumption distribution remained much higher than that of households in the top 20 percentile a year after the flood making more likely a long lasting impact on the nutritional status of these poor children (Del Ninno and Lundberg, 2005).

Another study may be illustrative of this conditional recovery. Looking at children aged 1224 months residing in households below and above the median value of pre-drought livestock holdings in Zimbabwe during the 1994/95 drought, Hoddinott and Kinsey (2001) found that the shock only affected the growth height of children residing in households with little livestock. This evidence seems to suggest that recovery is wealth differentiated, with the poor having more difficulties to catch up.

While for children living in wealthier households seems plausible to recover weight losses occasioned by low energy intake (e.g., caused by drought) and/or nutrient losses due to infection (e.g. caused by floods), it is important to stress the qualitative difference between weight and height as these reflect different dimensions of children's development: height-for-age levels below some benchmark observed in healthy populations (stunting) reflects the long-term effects of malnutrition, while weight-for-age (underweight) and weight-for-height (wasting) are believed to have a short duration. Moreover, while for the former, there is considerable evidence linking it to subsequent adult health, productivity and earnings, this is not the case for weight, considered mostly as a short-term indicator of nutrition. Hence, ultimately, and unlike height where recovery could have future economic benefits, the economic importance of catching up weight after disasters remains unclear (Hoddinott and Kinsey, 2001). Finally, and not least important, catching up remains an empirical issue. When studies have been able to measure disaster impacts over the medium to long-run, many of them suggest a serious and permanent effect on human capital, as discussed next.

\footnotetext{
${ }^{8}$ In this analysis, households were classified according to their level of direct exposure to the flood using a household's flood exposure index, which includes the depth of water in the homestead and in the house, and also the duration (number of days) of water in the house.'
} 


\section{Long-run Impacts on Human Capital through Child Malnutrition ${ }^{9}$}

The formation of human capital is an unfolding and cumulative process. From the womb and up until age two, the acquisition of adequate micro-nutrients and proper health care towards the newborn are the primary functions towards building human capital. As the person gradually grows up the vector of human capital investments broadens to incorporate schooling decisions while nutritional and health considerations remain important. Once the person enters into a productive stage of its life-cycle, some of the previous considerations recede in importance, especially formal educational, but not ongoing at-work-training and constant improvement of skills and productivity. This sequential formation of human capital entails that nutritional impacts as the ones described before can reverberate into the further processes of human capital accumulation if they are not properly and timely addressed. It is therefore no coincidence that most literature looking at the impact of natural disasters on human capital is concerned with their specific burden on children. And also that, in fact, the nutrition literature is the one that has best documented the negative impacts of disasters on human capital in the long-run. These impacts operate through a combination of three main different channels: increased morbidity and mortality, schooling outcomes and productivity.

\section{Persistent nutritional effects, increased morbidity and mortality}

Decreasing the incidence of malnutrition can be instantaneously vindicated in terms of reduced mortality. However, while the incumbent may avoid immediate death, the health disruptions occasioned by malnutrition in a woman may increase the risk of mortality when giving to birth (including the life of its off-springs). And even if death is avoided, the health consequences of malnutrition can become a lifetime drain on the household's resources due to the permanent need to treat those consequences.

The nutrition and food security literature have widely documented the effect that short-term blows to nutrition could have on children stunting. For instance, tracing the 1982-84 droughts in Zimbabwe in a group of 400 rural households, Alderman and colleagues (2006) found that the temporary hunger followed by stunting of those children aged between 12 and 24 months at the

\footnotetext{
${ }^{9}$ Parts of this section draw on previous work cited in de la Fuente and Dercon (2008).
} 
time of the drought -recognized as the most critical time for child growth- led them to lower height (2.3 centimeters) in late adolescence.

Nearly a decade later, another drought (1994-1995) also reduced the height of Zimbabwean children of the same age group by $15-20$ percent $(1.5$ and $2 \mathrm{~cm})$ a year after the drought relative to children from a control group (Hoddinott and Kinsey, 2001). And the gaps in growth remained unchanged four years after the drought: Children at 60-72 months in 1999 (who were initially 12-24 cm in 1995) had z-scores about 6 tenths of a standard deviation below that of comparable non-affected children (Hoddinott and Kinley, 2001).

Consistent with the findings in Zimbabwe, research conducted with data from Ethiopia by Porter (2008), shows that children either in uterus or less than 36 months of age and living in a village hardly struck by the 1984 drought-induced famine in that country were 3 centimeters (cm) shorter ten years after the shock compared to unaffected but otherwise similar children. A similar effect (3.03 cm loss) was encountered by Chen and Zhou (2007) for the attained height of rural adults exposed during childhood (i.e., born between 1959 and 1962) to the 1959-61 famine in China, the worst famine recorded in human history.

The fact that short-term nutrition shortfalls stay long after the drought in the form of reduced height can transform into persistent health effects. Indeed, attained body size at adulthood in case of deficit could lead to the early onset of chronic diseases and premature mortality among male due to increased risk of cardiovascular and obstructive lung disease (Fogel, 1994), though very little evidence for developing countries exists on this yet.

Maccini and Yang (2008) provide the best evidence on the disaster-nutrition-morbidity link in the long-run. Using the Indonesian Family Life Survey and community-specific rainfall information, the authors examine the effect in 2000 of weather conditions around the time of birth on the health of adults born between 1953 and 1974. After constructing an index from various individual health measures (self-reported health, natural log of lung capacity, height in centimeters, and days absent in work due to illness in the last four weeks), Maccinni and Yang were able to establish that more birth year rainfall leads to a higher (lower) propensity to report "very good" (poor and very poor) health status; higher lung capacity; and greater height in 
centimeters. For instance, women with 20\% higher rainfall in their year and location of birth attained $0.14 \mathrm{~cm}$ greater height, and fewer working days absent due to illness. ${ }^{10}$ Interestingly, all this impacts were only found for girls. According to the authors, the rainfall's positive effects on crop output-and thus household income- is what leads to variations in parents' abilities to purchase nutrition, medical inputs, and generally more nurturing environments for children. ${ }^{11}$

As will be shown in the following subsection, the fact that women born in years and places with higher rainfall are taller and have better self-reported health can lead to better educational and productivity outcomes later in life. But an enhanced maternal health could also avert further costs to society resulting from a disaster tthrough the increased risk of maternal mortality and the intergenerational transmission of poorer health status from the mother to its children. There is indeed some epidemiological evidence that taller adult women experience fewer complications during child birth, have children with higher birth weights and experience lower risks of child and maternal mortality (World Bank, 1993).

Children with low birth weight (LBW) have weaker immunity to infections and other diseases and higher utilization of outpatient services. In terms of mortality, children with LBW exhibit larger infant death rates than non-LBW. For example, the risk of mortality between 28 days and one year of age has been found to increase by nearly $11 \%$ for each pound difference among identical LBW twins in the U.S. (Conley, Strully and Bennet, 2003). Similar suggestive correlations between the risk of neonatal death and LBW are identified in data from many developing countries (Behrman, et al., 2004). As for maternal mortality, various studies suggest that anemia, often produced by iron deficiency due to malnutrition, is also strongly correlated with at least 20 percent of maternal deaths and adverse birth outcomes (Ross and Thomas, 1996; Brabin, Hakimi and Pelletier, 2001).

\footnotetext{
${ }^{10}$ The coefficients in three of these five individual health variables (height as well as both self-reported health variables) are statistically significantly different from zero at conventional levels.

11 According to Maccini and Yang (2008), the link between early-life conditions and health conditions later in life can be explained through the critical-period programming literature. This is the notion that the fetal stage and infancy are critical periods in physical development, and that early-life shocks can have long-lasting effects on health. When facing low nutrition or other adverse health conditions, the developing fetus or infant prioritizes the brain to receive limited resources, compromising the development of other organ systems. The damage is to some extent irreversible, and the individual is thus 'programmed' for worse health later in life.
} 
Certainly, poor maternal health leading to morbidity and mortality increases on their children can impose a large burden on societies given the resources needed to deal with these issues. Much less explored, but with potentially significant effects over children's health (and education) in the long-run is the death of parents. The orphans surviving from famines would be a case in point, especially given the extensive loss of life that has accompanied some droughtinduced disasters in Sub-Saharan Africa, such as the mid 1980's famine in the Horn of Africa. To the best of our knowledge there is no direct evidence on the impact of disaster-led orphanhood on human capital, but the case of HIV orphans can shed some light in this respect. By comparing a group of orphans from HIV-infected parents in Tanzania that reached adulthood (above 19 or older) by 2004, with a sample of non-orphans in the baseline period 1991-94, so that the effects are irreversible for both height and (most likely) for education, Beegle et al. (2008) found that losing one's mother during childhood reduces height at adulthood by about 2 $\mathrm{cm}$, and implies having about one less year of education than non-orphans.

\section{School attendance, progression, completed schooling and cognitive development}

The effects of disasters on malnutrition early in life can give way to the second mechanism through which natural hazards can have long-run effects on the formation of human capital through delayed enrollment and a lower number of grades accomplished. Malnourished children, relative to healthier children, are prone to start school later and to perform worse at school. While contentious, it appears that children's capacity to learn is diminished by the effects of malnutrition. Delays can translate into less school attainment due to the often positive association between age and returns to schooling (each extra year of school brings higher opportunity costs) while bad performance can turn into repeating more grades at school or dropping out earlier. According to some authors (Alderman et al. 2009), even if delaying school had no effect on the number of grades obtained, the children who postpone their entrance still tend to perform worse when at school.

Proving the causal effects of malnutrition on school entry age and grade achievement is more difficult than stating it. There may be factors that determine malnutrition and also influence subsequent educational attainments. For instance, parents with more interest in investing in their children may feed them better as well as enroll them in school earlier and keep them in school 
longer. This makes necessary to find determinants of nutrition that are of strong and persistent enough to affect a child's stature during early life, but still short-lived so as to not directly affect subsequent human capital investments including schooling (Alderman et al., 2009). Transitory weather events can meet both conditions.

A few studies have indeed employed community flood and drought weather shocks with individual variables (age and gender) to instrument early childhood nutritional status and thus separate the direct impact of nutrition on schooling from other factors that determine both outcomes jointly. These studies in rural Zimbabwe (Alderman, Hoddinott and Kinsey, 2006), rural Tanzania (Alderman, Hoogeveen and Rossi, 2009) and Pakistan (Alderman, 2001) have all collectively found that malnutrition reduces the probability of school initiation and the years of schooling attained. For instance, the study of the 1982-84 drought impact in rural Zimbabwe found that stunted children aged 12-24 months had delays in school enrolment (3.7 months) and reduced grade completion (0.4 grades) 13 to 16 years after the droughts (Alderman, Hoddinott and Kinsey, 2006).

Alderman, Hoogeveen and Rossi (2009) also find evidence of long lasting drought impacts on the human capital of Tanzanian children (in the region of Kagera) through the same link of slow height growth leading to delayed entrance and poorer achievements in schooling. Using panel data that covers the beginning and end of a 10-year period (1991-94/2004), the authors find that 0-5 age children exposed to a drought in 1991-94 suffered a decline in their average height of roughly one percent of the median of a reference population. And ultimately, by regressing the educational achievements of those same children during adolescence in 2004 on their early life height in percentage, they observe that malnutrition in childhood does affect the age of school entry and the number of grades achieved. Children who are severely malnourished face almost twice the risk of never attending school as well-nourished children. Simulations based on parameter estimates from this -and the Zimbabwean study suggest that protecting nutrition from natural disasters would have sizeable effects on school attainment. For this particular case, the authors find that if the height of a boy increased from $80 \%$ to $95 \%$ this would increase schooling by 0.93 years. 
An alternative way to establish the long-term effect of malnutrition on schooling would be through experimental variation in nutritional outcomes, for instance, randomizing nutritional interventions. Doing this would eliminate from the analysis any systematic preferences for investing in children's human capital. This is precisely what Behrman and colleagues (2003) were able to accomplish taking advantage of randomly distributed nutritional supplements at community level in Guatemala for children aged between 6 and 24 months. The benefited children were more likely to pass the first grade, have higher grade completion rate per year enrolled in school and attained higher achievement test scores in adulthood.

The results discussed in this section (and a few others not strictly connected with natural disasters and therefore omitted in this review)12 suggest that protecting the nutrition of children in early childhood in the aftermath of a natural disaster will have a palpable influence in their student performance (repetition rates and total schooling accomplished) later in life.

\section{Reduced physical productivity}

Up to this instance, it has been argued that individuals who were stunted as pre-schoolers due to the impact of a natural disaster can be dragged into negative health and educational outcomes in the longer term. But what does this means in terms of lost earnings? The literature suggests various pathways through which early-life malnutrition can lead to lower physical productivity when adult and reduced lifetime earnings. First, stunted pre-schoolers are likely to stay shorter as adults, and this lower height is associated with reduced earnings (maybe due to poorer health or lower physical strength) (Thomas and Strauss, 1997); Second, poor nutritional status at an early stage in life might develop into poorer cognitive skills. This could lead to perform worse at school (less learning or fewer grades attained), and ultimately to exhibit lower productivity in labor markets (Alderman et al., 2009); And third, the premature onset of chronic diseases due to adverse nutritional outcomes in childhood could turn into reduced life expectancy resulting in shorter productivity or lifetime earnings (Alderman, Hoddinott and Kinsey, 2006).

\footnotetext{
${ }^{12}$ Glewwe, Jacoby and King (2001) track children from a large panel sample collected in the Philippines and -after controlling for several confounding factors- found that those better nourished were more likely to start school earlier and performed better, i.e. repeated fewer grades. The magnitude of the differences is significant: a 0.6 standard deviation increase in the stature of malnourished children would increase school attainment by about a year.
} 
It is hard to disentangle which above mechanism is most at play when documenting the earning repercussions of natural disasters. For instance, many papers have shown that child malnutrition working through lower adult stature has negative effects on earnings. This association has been modeled in different settings and validated with rich longitudinal data from rural India, Guinea, Philippines, Brazil (Behrman and Deolalikar, 1989; Haddad and Bouis, 1991; Foster and Rosenzweig, 1993; Glick and Sahn, 1997; Thomas and Strauss, 1997). And the magnitude of the effect is non-trivial. Estimates from Thomas, et al. (1997), for instance, indicate that the earnings-elasticity for urban Brazil is around 2-2.4.

In specific relation to weather shocks, the paper by Maccini and Yang (2008) show effects of early-life rainfall on the socioeconomic status of adult Indonesian women through a similar mechanism: women with 20\% higher rainfall in their year and location of birth attained $0.14 \mathrm{~cm}$ greater height, finished 0.15 more years of schooling, lived in households with 5.2\% higher expenditures per capita, and had spouses with 5.1\% higher earnings. Crucial for their proposed interpretation, they did not find evidence that adult women's health status and education levels matter directly for adult socioeconomic status, apart from indirect effects via spousal quality. Interestingly, results are not significant for men, suggesting that investments in boys are better protected from negative shocks that those in girls. This goes back to our earlier point endorsing what a larger body of literature finds in the sense that women and children's human capital seem especially vulnerable to natural disasters.

Unlike the previous two examples, Hoddinott and colleagues (2008) were able to establish that poor nutrition has a large effect on earnings through its impact on the cognitive skills of individuals, and not via height, health or strength shortcomings. Drawing on a panel of 1424 individuals (aged 25-42 years) between 2002 and 2004, which accounted for 60\% of 2392 children (aged 0-7 years) who had been enrolled in a nutrition supplementation trial fielded in rural Guatemala during 1969-77, the authors model the impact of stunting (main right hand dummy variable) on wages (log of income earned per hour worked) in adulthood. By using the nutrition intervention as an instrumental variable (to proxy the nutritional status of children) they find a causal link between stunting and adult wages for men (46 percent increase in average wages for those individuals who received the supplement during 0-36 months of age). Subsequently, they regress wages on different measures for cognitive abilities (for instance, 
reading and vocabulary test scores) and physical strength, to find large effects from the former on earnings. For example, a one standard deviation increase on a reading/vocabulary test raises hourly returns to labor by about $40 \%$. Finally, by regressing the same measures of cognitive abilities against dummies for stunting they were able to establish that the causality by which nutrition affects economic productivity runs from stunting to lowered cognitive skills to lower wages.

Finally, there are studies which establish an association between hazard-induced damages to the nutritional status of children and the productivity of that same individual later in life, but cannot disentangle the causal path through which stunting lowers wages. Looking back at the 1982-84 drought in Zimbabwe and using the values for the returns to education and age/job experience in the Zimbabwean manufacturing sector, Alderman, Hoddinott and Kinsey (2006) found that 16 years later those children affected by the drought had 7 percent loss of lifetime (extrapolated) earnings.

The previously mentioned study by Alderman and colleagues (2009) in the Kagera region of Tanzania also revealed that a drought back in 1991-94 affecting children aged 0-5 had a smaller, but still significant impact of their average lifetime earnings of about 1 percent. According to Alderman (2009) while this is much smaller that the estimate for Zimbabwe -in part because the age group in Tanzania is not restricted to the first two years of life usually considered the most critical- it is still over \$100 in present value when future earnings are discounted at a 3 percent discount rate. Both the Zimbabwe and Tanzania studies estimate returns to schooling and then factor them into simulations to come up with streams of monetary benefits perceived during lifetime (changing assumptions from estimates obtained about the additional years of schooling achieved imputed to better nutritional status).

Chen and Zhou (2007) exploit variations across regions and cohorts for constructing difference-in-difference estimations on the health and economic effects of the 1959-61 famine in rural China. They find that exposure to the famine in early life was associated with lower height and income during adulthood. For the 1959 cohort for instance, the annual per capita agrarian income decreases by approximately $2 \%$ if the excess death rate in the region of birth increases by 
1 person per thousand. 13 While an implicit connection may exist between height and earnings due to the effects encountered, the study estimates are derived from a set of reduced-form regressions, leaving unexplored the specific mechanisms through which exposure to famine during early childhood (including health outcomes) translates into economic outcomes later in life.

All three last studies in Zimbabwe, Tanzania and China suggest that even ignoring the pathway through which malnutrition (triggered by drought, famine or any other disaster) may affect wages (because earnings were extrapolated or estimated through reduced-form regressions), safeguarding the nutritional status of children in the aftermath of a disaster can have economic payoffs later in life.

Natural disasters can also affect the nutritional status of adults with potential consequences for their physical productivity and earning capacity. According to Dercon and Krishnan (2000), poor rainfall in drought-affected communities in Ethiopia during 1994-95 lowered the Body Mass Index (Weight in kilograms divided by squared height in meters) of those adults residing in households with low landholdings by about 0.9 percent. Moreover, clear correlations were found between this effect on malnutrition and the ability of adults to perform standard tasks, such as hoeing a field or carrying water. In Zimbabwe, while assessing the impact of 1994-95 drought across different members of a group of households surveyed, Hoddinott (2006) found that women's body mass fell by about 3\%, while no impact on men's health was found. With good rains the following year, however, the effects in this case were temporary with women regaining much of the lost body mass. ${ }^{14}$

Overall, there are two key messages to take away with regard to the persistence of disaster impacts on human capital via malnutrition. First, one should be conscious that the evidence base is still weak and likely context specific, partly due to the lack of data available for this purpose. There is still a need to understand better why nutrition impacts can vary according to the type of

\footnotetext{
${ }^{13}$ Excess mortality was employed to measure the degree of famine exposure per region, defined as the deaths exceeding those that would have occurred under prevailing normal conditions.

${ }^{14}$ In non-disaster contexts, a few studies have also found clear links between adult calorie intake and productivity. For instance, using data on caloric intakes and addressing observed and unobserved heterogeneity, Thomas, et al. (1997) find that wages in urban areas of Brazil were positively determined by energy intakes, particularly among workers with low intake levels. A similar effect has been identified with data from Philippines (Foster and Rosenzweig, 1995). These studies provide a way of expecting disaster impacts on productivity through their effects on adult health, provided this later situation actually takes place.
} 
disaster, regions and groups of population affected. As Dercon (2009) notes, to conduct research on long-term impacts of disasters very long term panel data are needed, since recall questions tend in general to provide unreliable evidence. Very few countries have surveys that meet this requirement. However, the few cases where careful analysis has been possible have actually uncovered some persistent effects of natural disasters on human capital. This gives way to believe that if further studies are replicated in this direction similar disturbing effects might continue to be found.

In sum, there is a large literature that links natural disasters to nutrition and it points to strong negative effects both on short-term nutritional measures - such as weight for height - and long-term ones - such as height for age. While the evidence is more abundant for children that on adults it all po ints in the same direction. And very importantly, there is mounting evidence that these impacts are long-lasting.

\section{Effects of Disasters on Health}

Health is often the most critical issue during the initial emergency period after a disaster. Natural disasters, such as floods, hurricanes, and earthquakes, have been associated with moderate to severe physical and psychological effects.

\section{Mortality}

Every year, around 60,000 people die worldwide in natural disasters. Deaths associated with natural disasters are reported in the EM-DAT disaster database (Centre or Research on the Epidemiology of Disasters, Public Health School, Catholic University of Louvain, Belgium) and two reinsurance company databases - MunichRe and SwissRe. These databases include little epidemiologic information (age, gender, cause), however. The ten most devastating natural disasters since 1970, according to the number of causalities, are listed in Table `.

Excluding droughts, earthquakes account for the largest number of disaster-related deaths. Indeed, over the past 20 years, the number of people killed in earthquakes is approximately equal to the number of people killed in all other types of disasters together. Storms (hurricanes, 
cyclones and storm surges) account for about a quarter of disaster-related deaths over the past 20 years and hydrological disasters (floods and landslides) for about one-sixth.

Table 1. The 10 Most Devastating Disasters Ranked by Number of Victims - 1970-2008

\begin{tabular}{|l|l|l|l|}
\hline Victims & Date & Nature of the disaster & Area(s) \\
\hline 300,000 & 1970 & Drought & Ethiopia \\
\hline 300,000 & 1970 & Storm and flood catastrophe & Bangladesh \\
\hline 255,000 & 1976 & Earthquake & China \\
\hline 220,000 & 2004 & Earthquake, tsunami in Indian Ocean & Indonesia, Thailand \\
\hline 150,000 & 1983 & Drought & Sudan \\
\hline 138,000 & 1991 & Tropical cyclone Gorky & Bangladesh \\
\hline 133,655 & 2008 & Cyclone Nargis & Myanmar \\
\hline 87,476 & 2008 & Earthquake & China \\
\hline 73,300 & 2005 & Earthquake & Pakistan, India, Afghanistan \\
\hline 66,000 & 1970 & Earthquake & Peru \\
\hline
\end{tabular}

While in earthquakes it is clearer why people die, in other disasters - like floods - a larger variety of causes can be at heart. Ahern et.al. (2005), in their review of the epidemiological evidence on the health impact of floods, gather studies that look at the cause of deaths during these events. Based on evidence from flash floods in rich countries, most deaths arise from drowning and most often, take place when vehicles are swept away by floodwaters. Information on the risk factors is limited but the studies suggest that men have a higher probability of dying, while among those drowning at home, elderly are the most vulnerable. In developing countries, similarly, the evidence on floods suggests that drowning and injuries are the most common causes of mortality.

Whereas many of the deaths associated with natural disasters are non-preventable, many in fact are. The majority of deaths from natural disasters are caused by building collapse during earthquakes and most occurred in developing countries - despite the availability of the needed technology to ensure that buildings resist the tremors from quakes (Kenny, 2008). Kenny (2008) points at regulation failures and poor quality of the buildings materials used (due to limited capacities and corruption), in addition to the low cost-benefit analysis of some high-tech 
interventions, as the reasons behind the much higher mortality risk from earthquakes in the developing world.

More generally, Kahn (2005) examines in a cross-country sample between 1980 and 2002, the broader question of why developing countries suffer more deaths from natural disasters than their developed counterparts, despite the fact that the latter do not experience fewer natural hazards. The author finds that the level of economic development, institutional quality and democratic governments are all associated with fewer deaths for a given number of natural disasters.

Mortality risks arising from natural disasters seem to further differ across both gender and age groups (Box 1). In the US and Europe the death rate in floods and hurricanes is higher for men than women (Jonkman and Kelman, 2006). However, in developing countries women often account for a higher proportion of disaster deaths than men. The Asian Development Bank reports that $61 \%$ of the deaths in cyclone Nargis were women, for example, as were $70 \%$ of the deaths in the Indian Ocean Tsunami and 91\% of the deaths in the 1991 cyclone in Bangladesh (ADB, 2008 cited in Cropper and Sahin, 2009). In terms of age, Noji (1997) states that during earthquakes adults over 60 and children are at increased risk of death compared to other population groups.

Infant mortality has also been shown to increase in relation to El Niño in Ecuador (Vos et.al, 1999). In 1982-3, el Niño led to a substantial increase in infant mortality in the regions affected. In particular, the infant mortality rate increased from 52 per thousand before the disaster to 65 per thousand afterwards. A reduction in the coverage of immunization in 1983 is considered to have contributed to this increase in child mortality. But as in the previous cases, the life-threatening effects on children can be gender differentiated. In a group of 4,118 households in 16 states of India surveyed from 1969 to 1971, child mortality rates increased during periods of very low rainfall and were significantly higher for girls than for boys (Rose, 1999). As for mortality among the elderly, the first population-based study of earthquake injuries and deaths reports that during the 1998 earthquake in Armenia the death rate for persons over 60 doubled that of persons under 60 (Armenian et al. 1997). 
This different degree of vulnerability across gender and age further means that they can have an important effect on the gender gap in life expectancy. Neumayer and Pluemper (2007) use cross-country evidence to examine the effect of a diverse range of natural disasters in the period 1981-2002 on the change in the gender gap in life expectancy in a sample of 141 countries. They find that natural disasters, on average, kill more women than men or at an earlier age, meaning that natural disasters lower the life expectancy of women more than that of men. For most countries, this means that natural disasters narrow the gender gap in life expectancy. Moreover, the authors find that the intensity of disasters (measured by the ratio of causalities to population) is positively correlated with a larger differential effect on women's life expectancy. These effects, however, are reduced the higher is the socio-economic status of women.

\section{Box 1}

\section{Vulnerable Groups during the Indian Ocean tsunami}

On December 2004, a massive earthquake struck off the west coast of Northern Sumatra. This led to the most destructive series of tsunamis in recorded history, affecting up to 14 countries around the Indian Ocean. Indonesia, Sri Lanka, the Maldives, India and Thailand were the hardest hit with entire coastal zones being destroyed, and the tsunamis causing damage up to $3 \mathrm{~km}$ inland in some cases.

The magnitude of the tsunami disaster is dramatically captured by the death tolls: over 227,000 people lost their lives and some 1.7 million were displaced. This raw death toll, however, masks the disproportionate effect which the tsunamis had over some of the most vulnerable groups. In the Maldives those aged 65 or over, though comprising only 3.1 per cent of the population, accounted for 17.3 per cent of the deaths. Elsewhere the tsunami typically claimed more people under-15s and over-50s, with countries varying as to which of these two groups had the highest mortality rates.

Substantial gender imbalances in terms of fatalities were also present. Several studies across Indonesia, Sri Lanka and India looking at the mortality risk for females compared to males found consistently higher ratios for females varying from 1.2 (1.2 times as many women died) to 2.1, with wide variations for individual villages. Overall, the tsunami killed 40,000 to 45,000 more women than men.

Some of the reasons given for the gender and age differences in survival rates in these disasters are usually related to strength and stamina, and the ability to swim or climb trees. For instance, one study in Tamil Nadu found that women who were able to swim were more than twice as likely to survive. However, it is clear that pre-existing vulnerabilities, whether socioeconomic, environmental, political, psychological, age- or gender-based, also contributed to the multiple differentiated impacts cited. In women, for instance, a number of factors contributed to their particular vulnerability before, during, and after the tsunamis: a lack of information about evacuation warnings and shelter options, culturally restricted mobility, and responsibilities within the family that make women stay behind to care for the young and the elderly. Moreover, governments not always recognised or advanced their property rights during the post-tsunami implementation of housing, relocation and livelihood strategies. During the response phase, female-dominated businesses, such as small-scale cottage industries and fish processing, were not always as visible as businesses run by men, and were less likely to be supported with livelihood recovery grants. There were also concerns about women being excluded from cash grant projects. In Sri 
Lanka, Oxfam found that women experienced difficulties in accessing benefits, especially cash payments and rations, because families are usually registered for government and insurance purposes under the man's name'. Similarly, in the Maldives, women with small businesses often had no official registration and because they could not prove that they had lost their livelihoods, they did not qualify for assistance.

Sources: Adams and Nagarajan, 2006; World Bank, 2006; Telford et al., 2006; Oxfam, 2005; World Bank, 2000, taken from de la Fuente (2007)

Even when the risk of death is higher at the moment of the natural disaster, mortality risks can stay high way after the disaster has passed. Bennet (1970) in a survey comparison of 316 flooded and 454 non-flooded households during the 1968 floods in Bristol (UK) found a 50 percent increase in all-cause-deaths in the affected group one year after the event, with the largest increases among those over 45 years of age. In addition, the author found a $76 \%$ rise in flooded men visiting the general practitioner and a doubling of the hospital referral rate among the affected. Puatch and Yang (2008), on the other hand, use inter-state variation in storm intensity from various hurricanes and storms in Mexico (in the period 1960-2003) to examine their impact on mortality. The authors show that storms have a positive effect on mortality rates, though the effect is no longer significant after one year has gone by (in partial opposition to Bennet (1970)).

More generally, floods and other types of natural disasters are associated with a wide range of illnesses that may or not lead directly to death. We turn to the impact of natural disasters on morbidity next.

\section{Morbidity}

As discussed in the conceptual framework, the first channel through which natural disasters can have an impact on the health status of an individual and a community is through their impact on health-related infrastructure.

Hospitals, health facilities and health services are a community's lifeline in normal times and are especially critical in times of disaster. Yet time and again, they have been severely damaged or left unable to function in the aftermath of disasters. There are countless examples of health infrastructures - from sophisticated hospitals to small but vital health centers — that have suffered this fate (Annex 2). On August 2007 in just two minutes, the city of Pisco, Peru 
lost $97 \%$ of its hospital beds to an 8.0 magnitude earthquake; in the October 2005 earthquake in Pakistan, 50\% of the health facilities in affected areas were completely destroyed; in December 2004, the tsunami in the Indian Ocean destroyed 61\% of the health facilities in Banda Aceh, Indonesia (Bathia, 2009a).

The importance of hospitals and all types of health facilities extends beyond the emergency response and direct life-saving role they play. They also help preserve a healthy environment in the aftermath of disasters, when sanitation issues and infectious diseases can be common. Once the immediate days after a disaster have passed, if not reestablished promptly, the destruction of a health facility can be life-threatening (for those out-patients who are attached to the health facility for treatment of long term illnesses, for example) or a prohibited additional economic burden (for poor families having to attend other health centers, probably further away).

But the effects of natural disasters on morbidity go well beyond those related to the loss of complementary infrastructure. A number of papers have documented the increase in morbidity induced by natural disasters, especially in developing countries, where morbidity rates are already high and health resources are scarce. Tracing a group of children aged between 0-5 years in rural households within Central Mexico on a biannual basis from 1998 to 2000, de la Fuente and Fuentes (2008) found strong and statistically significant evidence that children became more susceptible to (self-reported) diseases as a result of weather-related (flood, drought and hurricanes) and geological (earthquakes) shocks. For instance, children in those households affected by the extensive drought that took place between the second half of 1998 and the first half of 1999 had about 11 percent more probability of becoming ill than their counterparts in non-affected households.

Anderson (2000) analyzes the general health effects of the 1997 floods in Grand Forks (North Dakota) and East Grand Forks (Minnesota). The author takes advantage of the fact that both communities shared a single health care system and used clinic and hospital discharge records of the population of both groups to assess the reasons for accessing health care and the morbid conditions existing at the time of use of the service. Both the hospital (5.94\%) and the clinic (13.8\%) facilities experienced increases in visits by residents of the two flooded communities, especially among those over 40 years old. Older patients had more visits for 
diseases and ailments related to respiratory, musculoskeletal (back, joints, sprains and strains), and mental illness (anxiety, neuroses), while younger patients only paid more visits in relation to mental illness. Similarly, visits for pregnancy related complications significantly increased after the flood. Interestingly, while for women respiratory and musculoskeletal ailments were most common, for men, respiratory infections, circulatory diseases (heart disease, hypertension) and drug and alcohol problems became more acute.

Similarly, Malilay (1987) studied patterns of morbidity, health care utilization and dislocation trends in the area affected by the 1985 earthquakes in Mexico City during 9 months following the event. 504 households from twenty-eight randomly selected camps, or twenty-two percent of camp households, were surveyed eight months after the earthquake. A rate of 74.1 injuries per 1000 persons was found among the 60+ age group while a rate of 5.3 per 1000 was observed in children 6-14 years. Regression results indicated that age was significant in predicting injury. Although fear accounted for most perceived illnesses at the time of the earthquake, medical care was sought instead for chest pains, high blood pressure, and respiratory conditions.

Most attention in the literature, however, has focused on the relationship between natural disasters and infectious diseases. While ecological changes due to natural disasters can increase the potential of transmission of infectious diseases or people may be forced to enter in direct contact with contaminated water for example, the link between natural disasters and infectious diseases is often misunderstood. Floods and standing water are sources of malaria as well as other infectious diseases, but the risk factors of outbreaks are actually primarily related to population displacement (Watson, et. al, 2007). When large sections of a population stay in (crowded) emergency shelters and displaced they are put at risk in environments that often lack the appropriate sanitation and health facilities and clean water. Damages to drinking water and sanitation systems further increase the risk of contracting diarrhea, dengue fever and cholera. Risk of infectious diseases also increase with the endemic level of the ailment, the likelihood of disruption in public disease control programs and the altered individual resistance to disease arising from malnutrition, for instance (Wade, 2002). 
Water is one of the most common origins of infectious diseases. It is estimated that more than two million deaths are caused by waterborne infectious diseases each year, including cholera, typhoid, dysentery, and other diarrheal illnesses (Wade, 2002). Recent work has explored the link between natural disasters and waterborne diseases. Particular attention has been devoted to floods since these events often result in the release of untreated sewage and wastewater into the water supplies or land that could contaminate watersheds and crops. In addition, flooding can also mix animal and human waste with water sources or other areas. Cases of floods in Bangladesh and India, as well as excessive rainfall in the United States, Canada and Finland have all been associated with outbreaks of waterborne diseases.

Looking at the particular case of gastrointestinal illness ${ }^{15}$ - the most recurrent manifestation of waterborne disease - Wade (2002) documents an increase in its incidence in the aftermath of the 2001 floods of the Mississippi River. The data was obtained from a randomized group of 1,296 subjects that had been monitored since a few months before the disaster through a home drinking water trial. The effect found was more pronounced among those predisposed to the illness, namely the young (12 years and under), those with preexisting related conditions and those who consumed more unfiltered water.

In developing countries, waterborne diseases pose an important risk to health due to the often dire state of public water systems and poor water treatment processes. For instance, Vahaboglu (2001), in the context of the 1999 earthquake in Turkey, found that the established surveillance system identified an increase in the number of diarrhea cases. Similarly, in the aftermath of Hurricane Mitch in Nicaragua, a large increase in acute diarrhea was detected, in addition to respiratory ailments Campanella (1999). In particular, the author reports an almost tripling of the incidence of acute diarrhea as the number of cases went from 2,849 to 6,798 per 100,000 inhabitants from the year before the event to the year after. ${ }^{16}$

Some other water-related diseases are water-vectored and these include, for example, malaria, yellow-fever and dengue. Natural disasters can transform the disease environment,

\footnotetext{
${ }^{15}$ Gastrointestinal illness is typified by symptoms that include diarrhea, vomiting, nausea, abdominal pain and fever (Wade, 2002).

${ }^{16}$ Part of this difference, however, is due to the fact that data pre-hurricane is based on passive reporting from hospitals, while ex-post the data was collected through active surveillance (Campanella, 1999).
} 
having a direct effect on health. For instance, a drought can reduce reproduction grounds for mosquitoes carrying malaria. Following a hurricane in Haiti in October 1963, Seaman at.al (1984) found that the percentage of blood samples testing positive for malaria increased from 2\% in September 1963 to 26\% in March 1964, with more than 75,000 new cases. Pre-shock information on the prevalence of malaria existed thanks to a malaria eradication program that had been in place since 1960 and that tested for the disease every month in 100 centers all around the country.

Other studies have also examined the causal effect of natural disasters on malaria. Vos et.al (1999) find that El Niño event was associated with an increased incidence of malaria and other communicable diseases which are, as discussed above, usually linked to poor sanitary conditions. Having increased significantly in 1982-1983, it took more than one decade to bring the number of cases of malaria back to the level of the early 1980s in Ecuador. Similarly, the authors report that in the $1997 \mathrm{El}$ Niño, a similar increase in malaria was observed. In particular, the number of reported cases in 1997 was 17000 and 5,935 in the first five months of 1998. Leptospirosis, cholera and dengue were also observed to have spread.

As our conceptual model indicates, one additional channel through which a natural disaster can affect a child's health is through less frequent consultations or visits to the doctors. The existing evidence suggests that this, in fact, is a very relevant channel. Jensen (2000) in his study of rain shocks between 1986 and 1987 in Cote d'Ivoire, found that the percentage of sick children taken for consultation after a rainfall shock in 1986-87declined by around 1/3 for those who received the negative shock and increased slightly for boys in regions with normal rainfall. Likewise, Baez and Santos (2007), using longitudinal data in Nicaragua before and after Hurricane Mitch, found that -conditional on being sick - children in affected areas were $30 \%$ less likely to be taken for medical consultation, even though there was no significant difference on the prevalence of illness between affected and non-affected children.

In short, the evidence - although less robust and consistent than in the case of nutritional outcomes - suggests that natural disasters have an important effect on household members' mortality and morbidity risks, with important differences depending on gender and age. Similar patterns are also observed in the case of psychological effects, as discussed next. 


\section{Mental Health}

Following a traumatic event, many people - both children and adults - experience at least some symptoms of post-traumatic stress disorder (PTSD), depression, anxiety, somatic complaints and general mental morbidity (Batniji, et. al, 2006); and in the case of a natural disaster, it can affect those who personally experience the catastrophe, those who witness it, and those who pick up the pieces afterwards, including emergency workers and law enforcement officers (WHO, 2001). Psychological reactions to a natural disaster or an extreme event vary across individuals depending on their age, developmental level, personality, intellectual capacity and social network.

Some individuals are particularly vulnerable to postdisaster trauma because of preexisting psychosocial stressors (homelessness, foster care, exposure to violence, trait anxiety, etc), low socioeconomic status, or special needs (including cognitive delays and prior mental illness). These postdisaster reactions may not manifest themselves until well after the event and could persist for years (Madrid, et. al, 2006).

There is a growing body of evidence on the impact of natural disasters on the psychological sequelae after natural disasters. Hurricanes and earthquakes have typically been the more thoroughly studied disasters. The empirical evidence on the impact of natural disasters on individual's mental health is, as that corresponding to other aspects of human capital, hindered by the restricted availability of pre-shock information. But the existing evidence seems to suggest the existence of real risks to mental health, especially in those segments of the population that are already vulnerable to psychological trauma.

Hurricane Andre and Hugo, category 4 hurricanes, have been associated with moderate levels of PTSD among children (Belter, et. al, 1991 and Vernberg, et. al, 1996). Goenjian et. al (2001), similarly, found evidence of posttraumatic stress and depression, although more severe than in the other two cases, in the aftermath of Hurricane Mitch in Nicaragua - a category 5 storm. Earthquakes have also been shown to have a negative impact on the mental health of young adults and children. Roussos et. al (2005) find that children exposed more severely to the 
1999 earthquake in Ano Liosia in Greece presented deeper posttraumatic stress that those in a control community less affected. The 1988 Spitak earthquake in Armenia and the 1999 Chi-Chi earthquake in Taiwan have both also made evident the vulnerability of the young to traumatic events. In the case of Armenia, Goenjian et. al (1995) show that children were suffering, in addition to PTSD, from depression and separation anxiety. Chen et. al (2002), for the case of Taiwan, showed that the psychological effects were still present one year after the quake.

Similar conclusions are reached in relation to other types of disasters, although the evidence is scanter. Traumatic events experienced during the tsunami were significantly associated with symptoms of PTSD and depression, both among children and adults. Thienkrua et. al (2006) assessed trauma experiences and the prevalence of symptoms of posttraumatic stress disorder and depression among children aged 7 to 14 years in tsunami-affected provinces in southern Thailand. Two months after the tsunami, the prevalence rates of PTSD symptoms were 13\% among children living in camps, $11 \%$ among children from affected villages, and $6 \%$ among children from unaffected villages. For depression symptoms, the prevalence rates were $11 \%, 5 \%$, and $8 \%$, respectively. Having had a delayed evacuation, having felt one's own or a family member's life to have been in danger, and having felt extreme panic or fear were significantly associated with PTSD symptoms. Older age and having felt that their own or a family member's life had been in danger were significantly associated with depression symptoms. Prevalence rates of symptoms of PTSD and depression among these children did not decrease significantly over time, as reflected in follow-up surveys conducted nine months after the event.

In the same region and at the same time, van Griensven, et. al (2006) assessed the existence of symptoms of posttraumatic stress disorder, anxiety and depression among adults affected by the tsunami. Among adult survivors, elevated rates of symptoms of PTSD, anxiety, and depression were also reported 8 weeks after the disaster, with higher rates for anxiety and depression than PTSD symptoms. The authors found that mental health was worse among women, those exposed the most to the tsunami and those who had lost their livelihood in the event. Nine months after the disaster, the rates of those reporting these symptoms decreased but were still elevated. 
Also in the aftermath of the 2004 tsunami, de Mel et. al (2008) surveyed five times during one year staring in March 2005, 561 Sri Lanka microenterprise owners. In contrast to van Griensven, et. al (2006), however, mental health recovery from a given initial level depended largely on the time elapsed after the disaster and not on the degree of economic recovery of an individual's livelihood (as measured by business profits). Ten months from the occurrence of the tsunami, a return to normalcy had generally taken place. A similar finding was observed by Friedman et al. (2009) while exploring the medium-run consequences of PTSD and physical injury following the 2004 Tsunami in Aceh. After following up respondents interviewed prior to the tsunami for five years afterwards, the authors found that six to fourteen months after the tsunami those heavily affected display high scores of PTSD relative to those not affected, with exposure to trauma, loss of loved ones, and damage to economic resources all playing significant roles, as do background factors. However, as time has passed (1.5 years after up to present) much PTSD tended to fade away or get resolved over time, and very few long run consequences of initial PTSD were observed. These two results coincide with those obtained by Norris et. al (2004) after the 1999 floods and mudslides in Mexico, where PTSD initially declined and then stabilized during the two years of follow-up.

Many available studies on the effects of natural disasters on mental health focus specifically on children. Common manifestations of psychological trauma in young children include regression, clinging behavior, inattentiveness, aggressiveness, bed-wetting, somatic complaints, irritability, social withdrawal, nightmares, and crying. Longer-lasting effects may include depression, anxiety, adjustment disorders, posttraumatic stress disorder, and interpersonal or academic difficulties.

Lonigan et.al (1994), using cross-sectional evidence from the aftermath of Hurricane Hugo in the US, find that three months after the storm, the presence of PTSD symptoms in 5,687 school-aged children was strongly related to the self-reported severity of the shock, degree of damage to their dwelling, and continued displacement. However, the authors find that the reported emotional reaction to the hurricane was even more strongly related to the existence of PTSD predisposing factors, especially trait anxiety or the tendency to respond with anxiety in the anticipation of a threatening situation. While the authors found no differential effect of the hurricane on the likelihood of developing PTSD according to age or gender, the higher rate of 
post-traumatic underlying symptoms among girls and the young, means that they are more likely to develop posttraumatic reactions in the aftermath of a disaster.

Most studies, in fact, have noted women to present stronger posttraumatic stress than men (Vernberg et. al, 1996; Goenjian et. al, 1995; Shannon et. al, 1994; Roussos et. al, 2005). Also, in their study of medium-run consequences of the tsunami in psycho-social disabilities in Aceh, Friedman et al. (2009) conducted an extensive review of 225 studies based on 132 conflict and natural disasters. They found that women are always more adversely affected in terms of psychosocial consequences by these events.

The evidence on age, however, is mixed. While Shannon et. al (1994) and Chen et. al (2002) report that younger children were more likely to test positive for PTSD than older children after Hurricane Hugo and the Chi-Chi earthquake in Taiwan, respectively, no systematic pattern was found after the Armenian earthquake of 1988 (Pynoos, 1993).

But the effects of a natural disaster on individuals' mental health depend not only on the exposure to the hazard and the pre-existing psychological and socio-economic risk factors. Natural disasters also indirectly affect the mental health status of children by affecting the living arrangements, economic opportunities and activities of the individual and his/her family and community. Lonigan et. al (1994) found that children whose parents were unemployed experienced more PTSD symptoms while social support was associated with a lesser psychological impact. Interestingly, the authors found that the support of teachers, more than that of parents or friends, was associated with lower levels of PTSD. Relocation, on the other hand, was not associated with a worsening of the mental status of children in the case of Spitak earthquake in Armenia (Najarian et. al, 1996) or the Chi-Chi earthquake in Taiwan (Soong et. al, 2000). Still, among the reallocated children in the case of Taiwan, those who did not live with their parents presented stronger symptoms of posttraumatic stress.

In sum, the existing evidence suggests strong links between natural disasters and the worsening of mental health among survivors. Notwithstanding some of the methodological limitations in these studies, results point at the presence of strong negative psychological effects of natural disasters, leading to posttraumatic stress, depression and anxiety. How long-lasting 
are these effects, however, is largely still an open question (Friedman et al. (2009). But, if they are in fact long-lasting, as Das et.al (2008) argues, a worsening of the individual's mental health may reduce labor supply, reduce productivity and increase health expenditures, increasing the risks of falling or staying in poverty. These persisting psychological effects of disasters should also be considered when devising a strategy to mitigate the impact of natural hazards.

\section{Taking Stock: What we do know and do not know}

This study has identified many of the limitations of the existing literature and some of gaps that need to be filled by the research community in terms of the microeconomic impact of natural disasters on human capital.

Important advances have been made in the empirical assessment of the impact of natural disasters on human capital. The use of robust econometric techniques, the increasing availability of high quality panel datasets and the creativity of researchers have led to a significant growth in the existing body of evidence in this area.

But these advancements have not been spread equally across the different aspects of human capital. In particular, the literature on nutrition and schooling, for instance, is more advanced that that of health - including mental health. In large part, this is due to data limitations. The fact that nutritional and schooling modules are routinely part of household surveys facilitates the production of evidence. With the exception of diarrhea, health and mental health outcomes are excluded most often from these surveys. Without information from household surveys, establishing the increased incidence of an illness that is due to natural disasters is often difficult to quantify because many of the surveillance mechanisms in place are underdeveloped. As a consequence, modest increases in most infectious diseases - for instance - are difficult to spot. Standardized supervision for common syndromes can help assess health impacts of natural disasters.

This review of the literature on the impact of natural hazards on human capital reveals that the potential detrimental effects can be large and long-lasting. Overall, there are two key messages to take away with regard to the persistence of disaster impacts on human capital. First, 
one should be conscious that the evidence is still limited, mainly due to the lack of data available for this purpose. As Dercon (2009) notes, to conduct research on long-term impacts of disasters very long term panel data are needed, since recall questions tend in general to provide unreliable evidence. Second, it is also necessary to pay attention to attrition given the multiple selection biases that could be at play (more educated and healthy individuals might be able to migrate as way of coping with shocks). This task is extremely challenging given the difficulties to track the same group of individuals over long periods of time. And obviously, one needs detailed data on the shocks and events that shape people's lives, but very few countries have surveys that meet all these information requirements. However, the few cases where careful analysis has been possible have actually uncovered some persistent effects of natural disasters on human capital. This gives way to believe that if further studies are replicated in this direction similar disturbing effects might continue to be found.

This study also has shown that natural disasters do not affect people equally and that both, inequalities in risk exposure and sensitivity to risk and in access to resources, opportunities and capabilities, put specific groups in a disadvantaged position. Poor women and children seem to be especially vulnerable to suffering large impacts to their human capital due to natural disasters.

The case of children is particularly worrying not only in its own right, but also since they constitute the future human capital of a country. To the extent that interruptions in schooling or a worsening of their nutritional status has a long-lasting effect, as the literature suggests they do, then the results explored in this paper indicate that natural disasters pose an additional threat to the accumulation of human capital, especially in communities that lack the appropriate safety nets and insurance mechanisms.

In terms of mental health, the evidence suggests that those with post-disaster difficulties at home - conflicts between family members, lack of electricity or water, changed living arrangements - presented higher posttraumatic distress. This points to the need for a comprehensive post-disaster mental health program for children and their families that includes assistance in problem-solving and coping mechanisms. Moreover, results also highlight the desirability of targeting specific subgroups of the population that are more vulnerable ex-ante to psychological disorders in the event of a catastrophe. 
This study also indicates that there are important synergies between the different outcomes of human capital, and that these interrelationships become increasingly important as children develop. This is the case of schooling and nutritional outcomes, for instance, where nutritional deficiencies early on in life is associated with lower schooling enrollment and lower school achievement.

Important shortcomings, however, remain. Much of the evidence is still often self-reported, cross-sectional and lacking an appropriate control group. The evidence - especially related to health outcomes - is, therefore, often based on correlations rather than on causal inferences. For instance, in a review of the literature on the impact of natural disasters on mental health, Norris (2005) finds only four studies out of 62 that were longitudinal, and only one based on more than two observations in time. Results should, therefore, be taken with caution.

Similarly, measurement of the intensity of natural disasters in an exogenous manner remains one of the main challenges in quantifying the impact of natural hazards, be it at the macro or microeconomic levels. The inability to appropriately identify the intensity of the shock and/or households affected by the event, means that it is often difficult to attribute a causal interpretation to the correlations found in the empirical evidence or even to find any statistically significant results.

In addition to these methodological limitations, there are some important aspects of the relationship between natural disasters and human capital that are yet to be explored or where more evidence is needed. Probably the most important area where more research is necessary relates to the channels through which natural disasters impact children's nutrition, health and schooling outcomes. While the adverse impact of natural disasters on children's nutrition and school enrollment - for example - are fairly well documented, we do not really know why we see those effects. In the case of Hurricane Mitch in Nicaragua, Baez and Santos (2007) find that while children's nutrition worsens significantly after the event, the same does not happen to the mother in the household. Is it that parents are not good agents for their children and when affected by a natural disaster they cut expenditures on them because they have no voice in the family? Is it that - given their credit and insurance constraints - this is the optimal decision to 
make? Or is it that mother's labor supply increases and they have less time to dedicate to children?

This latter channel, time, is particularly less well understood. If after a disaster, parents dedicate less (or more) time to the complementary or required activities, this can have important effects. This can be related to taking the time to go to the doctor with the child or helping the kid with his homework. Very little empirical work exists, however, that incorporates explicitly the changes in the use of a person's time induced by a disaster and their further effects on welfare outcomes. Our current understanding of the mechanisms at work in many of the results reviewed in this chapter would be enhanced by research in this area.

Having a clearer understanding of the mechanisms at work would allow policy-makers to target the right incentives and activities in their pre and post disaster aid programs in order to reduce the potential adverse effects of natural disasters on human capital. Moreover, this would also help in differentiating the likely effects of different types of disasters on different groups of a community. Here, as discussed in this paper, our knowledge is still limited.

A knowledge gap is also evident in relation to the long-term impact on human capital, as pointed out at different points in this review. While the studies that exist on this do point at the existence of long-lasting effects, the lack of long panel data sets is perhaps the most obvious limitation. Recent work, including Alderman, et.al (2008) and Alderman et.al (2006), has been able to explore these issues in the case of the long-run impacts of the worsening of nutritional status. However, the literature is still limited for reasons discussed above and the evidence on what makes some households or individuals more or less likely to recover (and what speed) is still in its infancy. Longitudinal data on the recovery process from a natural disaster is needed to examine the factors that hinder or contribute to a more speedy recuperation. For instance, in the case of mental health: do children take longer to recover than adults? Further evidence in this direction would help in designing differentiated interventions for those sub-groups particularly at risk.

Another question that still remains open refers to the impact on human capital of successive episodes of natural disasters and the overall perception of risk. Households may internalize 
future risks and modify their investment in human capital ex-ante as well as taking other preventive measures in anticipation of future losses if a disaster occurs. This reduction in human capital investment is not captured in the estimates discussed in this paper since it is nonobservable and an appropriate counter-factual is difficult to construct.

Further studies are also needed to evaluate the effectiveness of international and domestic post-disaster humanitarian assistance in mitigating the impact of the disaster. Any effective aid program should worry not only about targeting in the first step, but also about getting the type of intervention right. Is it better to provide cash to affected households, food aid or to help reconstructing schools and hospitals? The evidence on this is scarce but, for example, a number of studies have found that inter-household transfers in the aftermath of a disaster are partly crowded-out by public aid, especially when the latter is given in a form that is easily observable and verifiable by others such as housing or housing materials (Santos, 2007).

In short, our understanding of the impact of natural disasters on human capital has improved significantly in the past years and, while there are still a number of areas where further research is needed, the existing evidence carries with it significant lessons for policy makers. We explore these in the next section.

\section{Policy Implications}

The literature on natural disasters and human capital that has been reviewed in this paper puts forward a long list of desirable policy actions, including developing credit and insurance markets, promoting the efficient diversification of income sources, strengthening surveillance health systems, facilitating migration and retrofitting buildings, among many others. Our intention here is not to cover all of these, but rather to focus on key set of interventions that are less often discussed, but that are critical for mitigating the potential adverse effects of natural disasters on human capital.

Not all natural disasters are the same and not all people are the same. The evidence discussed in this study seems to indicate that not only are different natural disasters associated with different effects but also that vulnerabilities across a population exposed to a natural hazard 
also vary widely (See Annex 3). This implies there cannot be one set of solutions or policies that can be successfully generalized. Indeed, policy interventions should be tailored to the special needs of all these vulnerable groups to disasters — women, children, and the elderly —; and particularly sensitive to possible forms of discrimination against them during recovery. Involving women in the management of shelters, targeting female-headed households for support to lighten their workload, ensuring equity of treatment on employment as well as gender neutrality in housing acquisition and access to land ownership, and establishing workfare programs adapted to their needs, can all improve the recovery for women and households headed by women. Expanding early childhood development programs for newborn infants is also very important so as rebuilding schools — to avoid loss of human capital for those already in school-age and providing shelter for displaced people, including the elder.

Furthermore, this highlights that targeting is of uttermost importance. In general, the evidence surveyed in this study suggests that there is much to be gained from better targeting pre and post disasters preparation and aid programs. Especially in developing countries, targeting is usually done at the provincial level -and the community level at best. But if the final impact of a natural disaster is intrinsically linked to the vulnerabilities and risk factors of specific households or subgroups, then geographic targeting is not enough (Santos, 2007).

Conditional cash transfer programs (CCTs) have a great potential as instruments for public policy in the aftermath of disasters, especially in terms of protecting children and their human capital. As mentioned earlier, natural hazards in rural households in Central Mexico can have large effects in taking children out of school and in inducing them to increase their work participation. Yet, cash transfers conditional on sending children to school largely or completely protected children from the effect of these shocks on school enrolment. Nevertheless, the income effect of the transfers was still not sufficient to affect household behavior with respect to the use of child work in response to shocks (de Janvry et al., 2006). ${ }^{17}$ More importantly, thus far most conceived safety nets are still not flexible enough in their targeting and ability to scale up and respond to sudden and unexpected shocks like natural disasters. Indeed, the traditional mean-

\footnotetext{
${ }^{17}$ This seem to be downplayed by the study as child labor is done at no cost in terms of schooling due to the price effect of the conditional transfer, but other outputs on school attainment could be compromised posing further questions into the viability of the transfer scheme.
} 
tested or geographical targeting methods conceived to identify the structurally poor under cash transfer programs could be inaccurate to capture the transient poor resulting from climatic and geological hazards. Even if this issue gets sorted out, limited capacities on the ground can also become a severe constraint for any attempts at scaling up cash schemes, in some cases to the national level, especially in the context of longer-term social protection strategies. Technical and administrative capacities should thus be carefully assessed and built before any attempt to set up large-scale cash transfer programs with disaster-specific components (de la Fuente, 2009).

Furthermore, as argued above, not all disasters are the same; hence, not one-size solution fits all. For example, CCTs are more appropriate to protect children’s human capital while workfare programs are more adequate for reconstruction activities and the provision of employment.

But ex-ante, there is still much policy can do. We have made a lot of progress in terms of information systems - like early warnings, especially for weather related shocks, but we are still bad in reacting to those disasters. People often refuse to leave risky areas, for example, even when informed about an imminent risk. How to make better use of the existing systems and improving the dissemination of information - especially in remote areas - is critical. For those phenomena for which information systems are less developed - both because of technological and budgetary constraints - such as earthquakes, more research is needed to come up with appropriate and more affordable technologies. Many lives could be saved.

\section{At the end, many shortcomings come down to information, information and more}

information. We have highlighted in this review that many of the shortcomings in our understanding of the effects of natural disasters on human capital stem from the lack of appropriate data. In the future, it is important to incorporate disaster modules as a feature of regular household surveys, like LSMS, and link them to objective data of disaster occurrence such as rain data, ground shaking motions in earthquakes or declaration of disaster areas by local authorities. One example where rich information can be obtained from household data is the case of the Nicaraguan LSMS surveys and Hurricane Mitch, where the World Bank - having completed the regular survey a few months before the event, decided to conduct a special followup survey in affected households a few months later with the objective of collecting information 
on damages and coping strategies. While only affected areas where surveyed, the exercise is able to provide valuable information on the effects of the Hurricane and can be easily matched with non-self-reported criteria of the intensity of the shock. The costs and benefits of these exercises need to be rethought.

The policy to-do list is fairly long. Therefore, finding ways of creating the right incentives for individuals, households, communities and the private sector to take the ex-ante and ex-post measures available to them to mitigate the potential impact of natural disasters is an important part of the overall effort required. This study has shown that while natural disasters can have adverse long-lasting effects on human capital, there is much that policy can do about it.

\section{References}

Ahern, M. Kovats, S. Wilkinson, P. Few, R. and Matthies, F. (2005) "Global health impacts of floods: Epidemiologic evidence”, Epidemiologic Reviews, vol 27, pp36-46

Alderman, Harold. (2009) “Addressing the risks to nutrition from increasing climate variability” The World Bank. Washington, D.C.

Alderman, H., Hodditnott, J. and Kinsey, B. (2006) "Long-term consequences of early childhood malnutrition”, Oxford Economic Papers, 58, 3, pp450-474

Alderman, H., Hoogeven, H. and Rossi, M. (2008), "Preschool nutrition and subsequent school attainment: Longitudinal evidence from Tanzania”, forthcoming, Economic Development and Cultural Change

Alderman, H. and Paxson, C. (1994). "Do the Poor Insure? A Synthesis of the literature on Risk and Consumption in Developing Countries", in Bacha, E. L., editor, Economics in a Changing World, volume Development, Trade, and the Environment, London. Macillan, pp. 48-78

Anderson, J. (2000) "Health conditions associated with the greater Grand Forks 1997 flood disaster: Preto post flood seasonal and trend analysis with age and gender effects", PhD dissertation, The University of North Dakota

Batniji, R., van Ommeren, M. and Saraceno, B. (2006) "Mental and social health in disasters: Relating qualitative social science research and the sphere Standard”, Social Science and Medicine, 62, pp18531864 
Baez, Javier and Mason, A. (2008). “ Dealing with Climate Change: Household Risk Management and Adaptation in Latin America”, background paper for the 2008 World Bank Flagship Report on Climate Change in Latin American and the Caribbean, Washington.

Baez, Javier and Santos, I. (2007). “Children's Vulnerability to Weather Shocks: A Natural Disaster as a Natural Experiment”, working paper.

Baez, Javier. (2007). "Income Volatility, Risk-Coping Behavior and Consumption Smoothing Mechanisms in Developing Countries: A Survey”, Desarrollo y Sociedad, 58, March, Bogota, Colombia, pp. 37-83.

Barrera, F. and Pérez, F. (2005). "Consumption Smoothing: Empirical Evidence from Colombia and Nicaragua”, manuscript, Fedesarrollo, Bogota, Colombia.

Bhatia, Sanjaya. (2009). Guidance Note For Integration Of Disaster Risk Reduction Concerns In Bank Projects. Global Facility for Disaster Recovery and Reduction. World Bank. (Work in progress).

Beegle, K., Dehejia, R. and Gatti R. (2003). “Child Labor, Crops Shocks and Credit Constraints”, NBER Working Paper 10088.

Belter R., Dunn, S. and Jeney, P. (1991), “The psychological impact of Hurricane Hugo on children: a needs assessment”, Advances in Behaviour Research and Therapy, 13, pp155-161

Binswanger, H. and Rozensweig, M. (1993). "Wealth, Weather Risk and the Composition and Profitability of Agricultural Investments”, The Economic Journal, 103, pp. 56-78

Campanella, N. (1999) "Infectious diseases and natural disasters: the effects of Hurricane Mitch over Villanueva municipal area, Nicaragua”, Public Health Reviews, 27, 4, pp311-319

Carter, M., P. Little, T. Mogues and W. Negat. (2004). "Shocks, Sensitivity and Resilience: Tracking the Economic Impacts of Environmental Disaster on Assets in Ethiopia and Honduras”, Department of Agricultural \& Applied Economics, Staff Paper No. 489, University of Wisconsin.

Chen S., Lin, Y., Tseng, H., and Wu, Y. (2002), "Posttraumatic stress reactions in children and adolescents one year after the 1999 Taiwan Chi-Chi earthquake”, Journal Chinese Institute of Engineers, 25, pp597-608

Cord, L., Hull C., Hennet, C. and Van der Vink, G. (2008) "Climate Change and Poverty: An Integrated Strategy for Adaptation”, PREM Notes, Number 3, World Bank.

Cropper, Maureen and Sebnem Sahin (2009) "Valuing Mortality and Morbidity in the Context of Disaster Risks” Background paper for the joint World Bank - UN Assessment of Disaster Risk Reduction.

Das, J., Do, Q., Friedman, J. and McKenzie, D. (2008). "Mental health patterns and consequences: Results from survey data in five developing countries", Policy Research Working Paoer 4495, World Bank, Washington, DC

De la Fuente, A. (2007). “Climate Shocks and their Impact on Assets,” Paper \#23. Human Development Report 2007/2008. United Nations Development Programme. New York: Oxford University Press. 
. (2009). "Public Responses to Climatic and Geological Hazards” in K. Watkins, R. Fuentes and P. Seck, The Consequences of Risk on Human Development. Palgrave Macmillan. (forthcoming)

De la Fuente, A. and Dercon, S. (2008). "Disasters, growth and poverty in Africa: revisiting the microeconomic evidence”, Background Paper for the 2009 Global Assessment Report on Disaster Risk Reduction: 'Reducing Risk: Reducing Poverty', UNISDR/World Bank.

De la Fuente, A. and Fuentes, R. (2009). "The Impact of Climatic and Geological Hazards on Children Morbidity in Rural Mexico" in K. Watkins, R. Fuentes and P. Seck, The Consequences of Risk on Human Development. Palgrave Macmillan. (forthcoming)

De Janvry, Alain, Frederico Finan, Elisabeth Sadoulet, and Renos Vakis. (2006) "Can conditional cash transfer programs serve as safety nets in keeping children at school and from working when exposed to shocks?” Journal of Development Economics Vol. 79 (2), 349- 373.

Del Ninno, C. and Lundberg, M. (2005). "Treading water: The long-term impact of the 1998 flood on nutrition in Bangladesh”,Economics and Human Biology, 3, 67-96.

De Mel, S., Mckenzie, D. and Woodruff, C. (2008) "Mental health recovery and economic recovery after the tsunami: High-frequency longitudinal evidence from Sri Lankan small business owners“, Social Science and Medicine, 66, pp582-595

Dercon, S. (1996). "Risk, Crop-choice and Savings: Evidence from Tanzania”, Economic Development and Cultural Change, 44 (3), pp. 485-513.

. (2002) “Income Risk, Coping Strategies, and Safety Nets” The World Bank Research Observer Vol. 17 (2), 141-166.

. (2009) "Risk, Poverty, and Human Development: what do we know, what do we need to know?" in K. Watkins, R. Fuentes and P. Seck, The Consequences of Risk on Human Development. Palgrave Macmillan. (forthcoming)

Eswaran, M. and Kotwal, A. (1990). "Implications of Credit Constraints for Risk Behavior in Less Developed Countries”, Oxford Economic Papers, 42(2), pp. 473—482.

Fafchamps, M., Udry, C. and Czukas, K. (1998). "Drought and Savings in West Africa: Are Livestock a Buffer Stock?”, Journal of Development Economics, 55(2):273-482.

Ferreira, F. and Schady, N. (2008) “Aggregate economic shocks, child schooling and child health”, World Bank, unpublished

Foster, A. (1995). "Prices, Credit Markets and Child Growth in Low-Income Rural Areas”, The Economic Journal, 105 (430), pp. 551-570.

Friedman, Jed, Duncan Thomas and Elizabeth Frankerberg (2009) "Medium-run Consequences of Disaster Induced Psycho-Social Disability: Evidence from Aceh” The World Bank. (Work in progress)

García-Verdú, R (2002). “Evaluation of Conditional Income Support Programs: The Case of Mexico’s PROGRESA”, Doctoral Dissertation, University of Chicago. 
Garrison, C., Weinrich, M., Hardin S., Weinrich, S. and Wang, L. (1993) "Post-traumatic stress disorder in adolescents after a hurricane”, American Journal Epidemiology, 138, pp522-530

Goenjian A., Molina L., Steinberg, A., Fairbanks L., Alvarez M., Goenjian, H. and Pynoos, R. (2001) "Posttraumatic stress and depressive reactions among Nicaraguan adolescents after Hurricane Mitch", American Journal of Psychiatry, 158, pp788-794

Goenjian, A., Pynoos, R., Steinberg, A., Najarian, L., Asarnow, J., Karayan, I., Ghurabi, M. and Fairbanks, L. (1995) "Psychiatric comorbidity in children after the 1988 earthquake in Armenia", Journal American Academic Child Adolescent Psychiatry; 34, pp1174-1184

Goland, C. (1993), "Field Scattering as Agricultural Risk Management: A Case Study from Cuyo Cuyo, Department of Puno, Peru” Mountain Research and Development, 13 (4), pp. 317-338

Hoddinott, J. and Kinsey, B. (2000). “Adult Health in Time of Drought”, Food Consumption and Nutrition Division, Discussion Paper 79, International Food Policy Research Institute, Washington, D.C.

Hoddinott, J. and Kinsey, B. (2001). "Child Growth in the Time of Drought", Oxford Bulletin of Economics and Statistics, 63 (4), pp. 409-436

Hoddinott, J., Maluccion, J., Behrman, J., Flores, R., Martorell, R. (2008), "Effect of a Nutrition Intervention During Early Childhood on Economic Productivity in Guatemalan Adults, Lancet, 371, pp. 411-416.

Jacoby, H. and Skoufias, E. (1997). "Risk, Financial Markets, and Human Capital in a Developing Country”, Review of Economic Studies, 64 (3), pp. 311-335.

Jalan, J. and Ravallion, M. (1999). “Are the Poor Less Well Insured? Evidence on Vulnerability to Income Risk in Rural China”, Journal of Development Economics, 58 (1), pp. 61-81.

Jensen, R. (2000). “Agricultural Volatility and Investments in Children”, American Economic Review, Papers and Proceedings, 90 (2), pp. 399-404.

Kazianga, H. and Udry, C. (2006). "Consumption Smoothing? Livestock, Insurance, and Drought in Rural Burkina Faso”, Journal of Development Economics, 79 (2), pp. 413-446.

Kenny, C. (2008) "Why do people die in earthquakes? The costs, benefits and institutions of disaster risk reduction in developing countries”, draft, World Bank, Washington, DC

Kochar, A. (1995). "Explaining Household Vulnerability to Idiosyncratic Income Shocks”, American Economic Review, Papers and Proceedings, 85 (2), pp. 159-164.

Kochar, A. (1999). "Smoothing Consumption by Smoothing Income: Hours-of-Work Responses to Idiosyncratic Agricultural Shocks in Rural India”, The Review of Economics and Statistics, 81 (1), pp. 5061.

Lonigan, C., Shannon, M. Taylor, C. , Finch, A. and Sallee, F. (2004) “Children Exposed to Disaster: II. Risk Factors for the Development of Post-Traumatic Symptomatology”, Journal of Amer Academy of Child \& Adolescent Psychiatry 
Maccini, S. and Yang, D. (2008) "Under the weather: Health, schooling, and economic consequences of early-life rainfall”, forthcoming, American Economic Review

Madrid, P., Grant, R., Reilly, M. and Redlener, N. (2006) "Challenges in meeting immediate emotional needs: Short-term impact of a major disaster on children's mental health: Building resiliency in the aftermath of Hurricane Katrina”, Pediatrics, vol 117, no 5, pp448-453

Malilay, J. (1987) "The damnificados of Mexico City: Morbidity, health care utilization and population movement following the September 1985 earthquakes”, $\mathrm{PhD}$ dissertation, Tulane University

Morduch, J. (1990). "Risk, Production and Saving: Theory and Evidence from Indian Households”, draft, Harvard University.

Morduch, J. (1995). “Income Smoothing and Consumption Smoothing”, Journal of Economic Literature, 37(4), pp. 1569-1614.

. (1999) "Between the State and the Market: Can Informal Insurance Patch the Safety Net?” World Bank Research Observer, Vol. 14 (2), 187-207.

Morduch, J. (2003). “Consumption Smoothing Across Space: Tests for Village-Level Responses to Risk”, Stefan Dercon, ed., Insurance Against Poverty, Oxford University Press.

Mueller, Valerie and Osgood D. (2007a). "Long-term Consequences of Short-term Precipitation Shocks: Evidence from Brazilian Migrant Households,” The Earth Institute at Columbia University, unpublished manuscript.

Mueller, Valerie and Osgood D. (2007b). "Long-term Impacts of Droughts on Labor Markets in Developing Countries: Evidence from Brazil,” The Earth Institute at Columbia University, unpublished manuscript.

Najarian L., Goenjian, A., Pelcovitz, D., Mandel, F. and Najarian, B. (1996) "Relocation after a disaster: posttraumatic stress disorder in Armenia after the earthquake", Journal American Academy Children Adolescent Psychiatry, 35, pp374-383

Neumayer, E. and Pluemper, T. (2007) "The gendered nature of natural disasters: The impact of catastrophic events on the gender gap in life expectancy, 1981-2002”, Annals of the Association of American Geographers, 97(3), pp551-566

Norris, F. (2005) "Psychosocial consequences of natural disasters in developing countries: What does past research tell us about the potential effects of the 2004 tsunami?”, National Center for PTSD, Dartmouth College, Hanover, $\mathrm{NH}$

Norris, F., Murphy, A., Baker, C. and Perilla, J. (2004) "Postdisaster PTSD over four waves of a panel study of Mexico’s 1999 flood”, Journal of Traumatic Stress, 17, 4, pp283-292

Paxson, C. H. (1992). "Using Weather Variability to Estimate the Response of Savings to Transitory Income in Thailand”, American Economic Review, 82(1), pp. 15-34

Petal, Marla. (2008) Disaster Prevention for Schools Guidance for Education Sector Decision-Makers. Consultation Version. UNISDR. 
Porter, C. (2008) "The long run impact of severe shocks in childhood: Evidence from the Ethiopian Famine of 1984” University of Oxford. Department of Economics.

Pugatch, T. and Yang, D. (2008) “The economic and health effects of hurricanes in Mexico”, unpublished

Pynoos R., Goenjian, A., Tashjian, M., Karakashian, M., Manjikian, R., Manoukian, G., Steinberg, A. and Fairbanks, L. (1993), "Post-traumatic stress reactions in children after the 1988 Armenian earthquake”, British Journal Psychiatry, 163, pp 239-247

Rodriguez-Meza, J. and Gonzalez-Vega, C. (2004). "Household Income Dynamics and Poverty Traps in El Salvador”, draft, Ohio State University, Columbus, OH

Rosenzweig, M. and Wolpin K. (1993). "Credit Market Constraints, Consumption Smoothing, and the Accumulation of Durable Production Assets in Low-Income Countries: Investments in Bullocks in India”, Journal of Political Economy, 101 (2), pp. 223-244

Roussos, A., Goenjian, A., Steinberg, A., Sotiropoulou, C., Kakaki, M., Kabakos, C., Karagianni, S. and Manouras, V. (2005) "Posttraumatic stress and depressive reactions among children and adolescents after the 1999 earthquake in Ano Liosia, Greece”, American Journal of Psychiatry, 162, 3, pp530-537

Santos, I. (2006). "Risk-Sharing and the Role of Inter-Household Transfers after a Natural Disaster. Evidence from Hurricane Mitch in Nicaragua”, Doctoral Dissertation, Kennedy School of Government, Harvard University

Santos, I. (2007) "Disentangling the effects of natural disasters on children: 2001 earthquakes in El Salvador”, Doctoral Dissertation, Kennedy School of Government, Harvard University

Seaman, J., Leivesley, S. and Hogg, C. (1984) Epidemiology of Natural Disasters, Karger, Basel

Shannon, M., Lonigan, C., Finch, A. and Taylor, C. (1994), "Children exposed to disaster, I: Epidemiology of post-traumatic symptoms and symptom profiles”, Journal American Academic Child Adolescent Psychiatry, 33, pp80-93

Skoufias, E., (2001), "Progresa and Its Impacts on the Human Capital and Welfare of Households in Rural Mexico”, Research Report 139, International Food policy Research Institute, Washington, DC

Skoufias, E. (2002), "Rural Poverty Alleviation and Household Consumption Smoothing: Evidence from PROGRESA in Mexico”, Working Paper, IFPRI.

Skoufias, E. and Quisumbing, A. (2003). "Consumption Insurance and Vulnerability to Poverty: A Synthesis of the Evidence from Bangladesh, Ethiopia, Mali, Mexico and Russia”, manuscript, IADB and IFPRI.

Soong, T., Lee, Y., Huang, R., Liu, S. and Chen, Y. (2000) "A comparative study of post-traumatic symptoms between students living at Yu-Chih and relocating to Kaohisung after the Chi-Chi earthquake” in Proceedings of the International Workshop on Annual Commemoration of Chi-Chi Earthquake. Taipei, Taiwan, National Center for Research on Earthquake Engineering, pp308-317

Thienkrua, W., Lopes Cardozo, B., Chakkraband, S., Guadamuz, T., Pengjuntr, W., Tantipiwatanaskul, P., Sakornsatian, S., Ekassawin, S., Panyayong, B., Varangrat, A., Tappero, J., Schreiber, M. and van 
Griensven, F. (2006) "Symptoms of posttraumatic stress disorder and depression among children in tsunami-affected areas in Southern Thailand”, Journal of the American Medical Association, 296, pp 549559

Townsend, Robert. (1994). “Risk and Insurance in Village India”, Econometrica, 62 (3), pp. 539-91.

. (1995) "Consumption Insurance: An Evaluation of Risk- Bearing Systems in Low-Income Economies” Journal of Economic Perspective Vol. 9 (3), 83 -102.

Ureta, Manuelita. (2005). "Hurricane Mitch, Family Budgets and Schooling in Nicaragua”, manuscript, Department of Economics, Texas A\&M University.

United Nations Secretariat for the International Strategy for Disaster Reduction UN/ ISDR Secretariat/World Bank (2009). Global Assessment Report on Disaster Risk Reduction: 'Reducing Risk: Reducing Poverty'.

United Nations Secretariat for the International Strategy for Disaster Reduction (UNISDR Secretariat (2008) “Disaster Prevention for Schools Guidance for Education Sector Decision-Makers” Geneva.

Vahaboglu, H., Gundes, S., Karadenizle, A., Mutlu, B., Cetin, S., Kolayli, F., Coskunkan, F. and Dundar, V. (2001) "Transient increase in diarrhea diseases after the devastating earthquake in Kocaeli, Turkey: Results of an infectious disease surveillance study”, Clinical Infectious Diseases, 31, pp1386-1389

Vakis, R., Kruger, D., and Mason, A. (2004). “Shocks and Coffee: Lessons from Nicaragua,” draft, Human Development Department, Latin America and the Caribbean Region, World Bank, Washington, DC

Van Griensven, F., Chakkraband, S., Thienkrua, W., Pengjuntr, W., Lopes Cardozo, B., Tantipiwatanaskul, P., Mock, P., Ekassawin, S., Varangrat, A., Gotway, C., Sabin, M. and Tappero, J. (2006) "Mental health problems among adults in tsunami-affected areas in Southern Thailand”, Journal of the American Medical Association, 296, pp 537-348

Vernberg. E., Silverman, W., La Greca, A. and Prinstein, M. (1996) "Prediction of posttraumatic stress symptoms in children after Hurricane Andrew”, Journal Abnormal Psychology, 105, pp237-248

Vos, R., (1999). “Economic and social effects of El Niño in Ecuador, 1997-98”, Inter-American Development Bank Technical Paper Series POV-107, Washington, DC

Wade, T. (2002) "Does severe flooding increase the incidence of gastrointestinal illness? An analysis of the three data collection methods during a severe flood of the Mississippi River in 2001”, PhD dissertation, University of California, Berkeley, CA

Watson, J., Gayer, M. and Connolly, M. (2007) “Epidemics after natural disasters”, Emerging Infectious Diseases, 13, 1, pp1-5

Wong, G. and Godoy, R. (2003). "Consumption and Vulnerability among Foragers and Horticulturalists in the Rainforest of Honduras”, World Development, 31 (8), pp. 1405-1419.

World Bank. (2005a). "Shocks and Social Protection: Lessons from the Central American Coffee Crisis", Report No. 31857-CA 
World Health Organization (2001) The World Health Report 2001: Mental Health: New Understanding, New Hope”

Yamano, T., Alderman, H. and Christiaensen, L. (2005) "Child growth, shocks, and food aid in rural Ethiopia”, American Journal of Agricultural Economics, 87, 2, pp273-88

Yuyu Chen and Li-An Zhou. (2007) "The long-term health and economic consequences of the 1959-1961 famine in China” Journal of Health Economics, 26, pp. 659-681 
Annex 1. Recent Impact of Natural Disasters on Schools

(deaths in schools shown in bold)

\begin{tabular}{|c|c|c|}
\hline Year & Location & Effects \\
\hline 2008 & Myanmar & $\begin{array}{l}\text { 2,250 schools completely collapsed in Cyclone Nargis. Another } 750 \text { were severely } \\
\text { damaged. }\end{array}$ \\
\hline 2008 & NW China & $\begin{array}{l}\text { An estimated 10,000+ children died in their schools. An estimated 7,000 classrooms } \\
\text { were destroyed. }\end{array}$ \\
\hline 2007 & Bangladesh & Cyclone destroyed 496 school buildings and damaged 2,110 more \\
\hline 2006 & Philippines & $\begin{array}{l}\text { Super Typhoon Durian caused \$20m USD damage to schools including } 90-100 \% \text { of } \\
\text { school buildings in three cities and } 50-60 \% \text { of school buildings in two other cities. }\end{array}$ \\
\hline 2006 & $\begin{array}{l}\text { Leyte } \\
\text { Philippines }\end{array}$ & $\begin{array}{l}245 \text { children and their teachers died in a mudslide that buried the village elementary } \\
\text { school after } 5 \text { days of rain had ceased. }\end{array}$ \\
\hline 2006 & Uganda & $\begin{array}{l}13 \text { children died in a school dormitory fire where children were using candles for } \\
\text { lighting. }\end{array}$ \\
\hline 2005 & $\begin{array}{l}\text { Northern Pakistan, } \\
\text { Kashmir }\end{array}$ & $\begin{array}{l}17,000 \text { students died at school, and } 50,000 \text { were seriously injured, many disabled. } \\
10,000 \text { school buildings destroyed. } 300,000 \text { children affected. In some districts } 80 \% \\
\text { of schools were destroyed. }\end{array}$ \\
\hline 2005 & Gulf States, USA & $\begin{array}{l}56 \text { schools were destroyed and 1,162 were damaged. } 700 \text { schools were closed and } \\
372,000 \text { children displaced. } 73,000 \text { college students displaced. } \$ 2.8 \text { billion was spent to } \\
\text { educate displaced students for a year. }\end{array}$ \\
\hline 2004 & Indian Ocean & $\begin{array}{l}\text { A tsunami destroyed } 750 \text { schools in Indonesia and damaged 2,135 more. 150,000 } \\
\text { students without schools. } 51 \text { schools were destroyed in Sri Lanka, } 44 \text { in Maldives, and } \\
30 \text { in Thailand. }\end{array}$ \\
\hline 2000 & Cambodia & $\begin{array}{l}\text { Severe floods directly affected between } 500,000 \text { and } 1 \text { m.students in } 1,000-2,000 \\
\text { schools in } 8 \text { provinces. }\end{array}$ \\
\hline 2004 & Bangladesh & 1,259 school buildings were lost to floods and 24,236 were damaged. \\
\hline 2004 & Tamil Nadu, India & 93 children died in a fire due to explosion of a cooking gas cylinder \\
\hline 2005 & Bam, Iran & $\begin{array}{l}67 \text { of } 131 \text { schools collapsed, the remaining were heavily damaged. (10,000 school } \\
\text { children and 1,200 teachers died and more than } 32,000 \text { students were adversely } \\
\text { affected.) }\end{array}$ \\
\hline 2003 & Bingol, Turkey & $\begin{array}{l}84 \text { children and teachers die in collapsed school building in a moderate } \\
\text { earthquake. } 4 \text { schools collapsed. } 90 \% \text { of schools were impacted and education } \\
\text { disrupted. }\end{array}$ \\
\hline 2003 & Xinjiang, China & $\begin{array}{l}900 \text { classrooms in dozens of schools collapsed in earthquake } 27 \text { minutes before } \\
\text { thousands of children returned to their classrooms. Middle school collapsed killing at } \\
\text { least } 20 \text { students. }\end{array}$ \\
\hline 2003 & Dominican Republic & 18,000 students lost their classrooms. \\
\hline 2003 & oumerdes, Algeria & 103 schools destroyed, 753 severely damaged. Cost of rehabilitation $\$ 79$ million. \\
\hline 2002 & AbGarm & 16,500 students education disrupted when 8 schools collapsed and 137 were damaged. \\
\hline 2002 & Molise, Italy & 26 children and 1 teacher died in a school earthquake collapse. \\
\hline 2001 & Cariaco, Venezuela & 2 schools collapsed in an earthquake. 46 students died. \\
\hline 2001 & EI Salvador & $\begin{array}{l}85 \text { schools were damaged beyond repair. Replacement and repair cost } \$ 114 \mathrm{~m} .22 \\
\text { preschoolers and their teacher were killed in an aftershock a month later. }\end{array}$ \\
\hline 2001 & Arequipa, Peru & 98 school buildings seriously damaged by earthquake \\
\hline 2001 & Taiwan & A three-story school collapsed in the middle of the night. \\
\hline 2001 & Bhuj, India & $\begin{array}{l}971 \text { students and } 31 \text { teachers were killed by this earthquake, though most children } \\
\text { were outside for Republic Day celebrations. 1,884 schools collapsed, destroying } \\
5,950 \text { classrooms including } 78 \% \text { of public secondary schools. } 11,761 \text { school buildings } \\
\text { suffered major damaged with } 36,584 \text { classrooms unusable. }\end{array}$ \\
\hline 1999 & Pereira, Colombia & $\begin{array}{l}74 \% \text { of schools in } 2 \text { cities were damaged ( } 22 \text { in one city alone were destroyed). } \\
\text { Children were outside for lunch. }\end{array}$ \\
\hline 1999 & Chi Chi, Taiwan & $\begin{array}{l}51 \text { schools collapsed and } 786 \text { were damaged. Cost of school reconstruction and repair } \\
\text { was } \$ 1.3 \text { billion }\end{array}$ \\
\hline 1999 & Kocaeli, Turkey & $\begin{array}{l}43 \text { schools were damaged beyond repair and hundreds more damaged. School was } \\
\text { suspended for hundreds of thousands of children for } 4 \text { months. }\end{array}$ \\
\hline 1998 & Bangladesh & Flooding destroyed 1,718 school buildings and 12,000 were damaged. \\
\hline 1998 & Eastern Nepal & 1,200 schools destroyed or heavily damaged. \\
\hline 1997 & Ardakul, Iran & Primary school collapse killed 110 students (earthquake). \\
\hline
\end{tabular}




\begin{tabular}{|c|c|c|}
\hline 1997 & Cariaco, Venezuela & 2 schools collapsed in earthquake, killing 46 students. \\
\hline 1993 & Maharashtra, India & $\begin{array}{l}48 \% \text { of the } 8,311 \text { killed were under the age of } 14 \text {. Many schools were destroyed by } \\
\text { earthquake. }\end{array}$ \\
\hline 1992 & Erzincan, Turkey & A 6 story medical school collapsed in moderate earthquake, burying 62 students \\
\hline 1989 & El Asnam, Algeria & 70-85 schools collapsed or severely damaged in earthquake. \\
\hline 1988 & Udayapur, Nepal & 6,000 schools destroyed in earthquake. \\
\hline 1988 & Yunan, China & 1,300 schools destroyed in earthquake \\
\hline 1988 & Spitak, Armenia & $\begin{array}{l}2 / 3 \text { of the } 25,000 \text { earthquake deaths were school children killed in their schools. } \\
400 \text { children died in } 1 \text { school alone. } 32,000 \text { children were evacuated }\end{array}$ \\
\hline 1985 & Mexico City, Mexico & Several schools collapsed in the early morning before school started. \\
\hline 1964 & Anchorage, Alaska & $\begin{array}{l}\text { Half of the city's schools were severely damaged by an earthquake during school hours, } \\
\text { however the school was unoccupied due to the Good Friday holiday. }\end{array}$ \\
\hline 1963 & Skopje, Macedonia & $\begin{array}{l}44 \text { schools ( } 57 \% \text { of urban stock) were damaged by earthquake, affecting 50,000 } \\
\text { children. }\end{array}$ \\
\hline 1958 & Chicago, USA & 92 students and 3 adults died in a fire at Our Lady of the Angels School \\
\hline 1952 & Sapporo, Japan & 400 schools collapsed in the earthquake. \\
\hline
\end{tabular}

Source: Petal (2008)

\section{Annex 2. Impact of Natural Disasters on Health Facilities in Latin America and the Caribbean}

\begin{tabular}{|c|c|c|c|}
\hline $\begin{array}{l}\text { Location and } \\
\text { Event }\end{array}$ & Year & Type of disaster & Effects \\
\hline $\begin{array}{l}\text { Mexico City- } \\
\text { Mexico }\end{array}$ & 1985 & Earthquake 8.1 & $\begin{array}{l}\text { Structural collapse of five hospital facilities and major } \\
\text { damage to another } 22 \text {. At least } 11 \text { facilities evacuated. Direct } \\
\text { losses estimated at US\$ } 640 \text { million. }\end{array}$ \\
\hline $\begin{array}{l}\text { San Salvador- } \\
\text { El Salvador }\end{array}$ & 1986 & Earthquake 5.4 & $\begin{array}{l}\text { Over } 11 \text { hospital facilities affected: } 10 \text { evacuated and one } \\
\text { condemned; 2,000 beds were lost. Total damage estimated at } \\
\text { US } \$ 97 \text { million. }\end{array}$ \\
\hline Peru & 1997-1998 & $\begin{array}{l}\text { Floods associated with } \\
\text { El Niño }\end{array}$ & 15 hospitals, 192 health centers and 348 health posts affected. \\
\hline $\begin{array}{l}\text { Dominican } \\
\text { Republic } \\
\text { Hurricane } \\
\text { Georges }\end{array}$ & 1998 & Hurricane; Category 3 & 87 hospitals and health centers damaged of destroyed. \\
\hline $\begin{array}{l}\text { Saint Kitts and } \\
\text { Nevis. } \\
\text { Hurricane } \\
\text { Georges }\end{array}$ & 1998 & Hurricane; Category 3 & $\begin{array}{l}\text { Joseph N. France Hospital in Saint Kitts suffered sever } \\
\text { damages; } 170 \text { beds lost. }\end{array}$ \\
\hline $\begin{array}{l}\text { Honduras } \\
\text { Hurricane } \\
\text { Mitch }\end{array}$ & 1998 & Hurricane; Category 5 & $\begin{array}{l}78 \text { Hospitals and health centers damaged or destroyed. } \\
\text { Honduras' national health network severely affected and } \\
\text { rendered inoperative just as over } 100,000 \text { people needed } \\
\text { medical attention. }\end{array}$ \\
\hline $\begin{array}{l}\text { Nicaragua, } \\
\text { Hurricane } \\
\text { Mitch }\end{array}$ & 1998 & Hurricane; Category 5 & 180 Hospitals and health centers damaged or destroyed. \\
\hline $\begin{array}{l}\text { Armenia, } \\
\text { Colombia }\end{array}$ & 1999 & Earthquake 5.8 & 61 health facilities damaged. \\
\hline El Salvador & 2001 & Earthquake 7.6 & $\begin{array}{l}1,917 \text { hospital beds ( } 39.1 \text { percent of the country's total } \\
\text { capacity put out of service. Affected hospitals include San } \\
\text { Rafael Hospital, Rosales Hospital San Juan de Dios (San } \\
\text { Miguel), and San Pedro (Usulután) and the Oncology } \\
\text { Hospital. }\end{array}$ \\
\hline Bolivia & 2002 & Hail and heavy rains & $\begin{array}{l}57 \text { dead. Functional and structural collapse of the } \\
\text { Policonsultorio de la Caja Nacional. }\end{array}$ \\
\hline Argentina & 2003 & $\begin{array}{l}\text { Flooding due to rivers } \\
\text { overflowing }\end{array}$ & $\begin{array}{l}\text { Severe damage to Dr. Alassia's Children's Hospital and the } \\
\text { Vera Candiotti Rehabilitation Hospital as well as } 14 \text { health } \\
\text { centers of the } 49 \text { that served Health Area V in Argentina. }\end{array}$ \\
\hline
\end{tabular}

Source: PAHO from Bhatia (2009) 
Annex 3. Effects of Natural Disasters on Human Capital by Type of Disaster

\begin{tabular}{|c|c|c|c|c|c|c|}
\hline \multirow[b]{2}{*}{ Type of disaster } & \multicolumn{6}{|c|}{ Impacts on: } \\
\hline & Incomelassets/consumption & Education & Child labor & Nutrition & Heatth & Mental health \\
\hline Droughts & 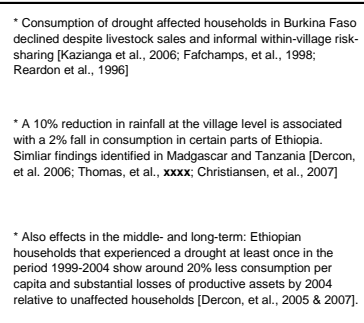 & 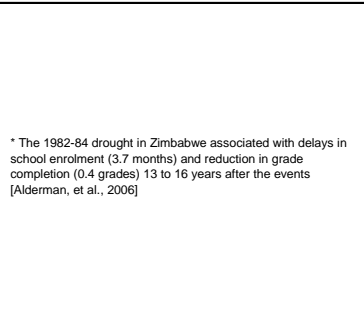 & & 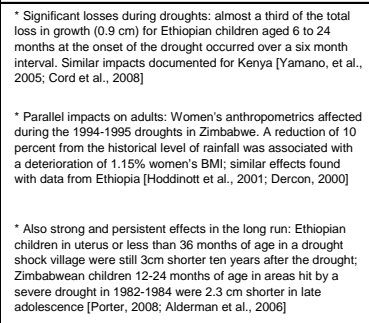 & 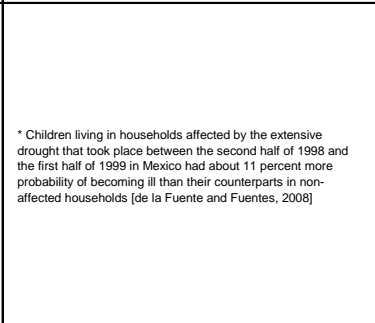 & \\
\hline Floods & & & & 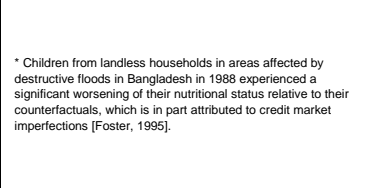 & 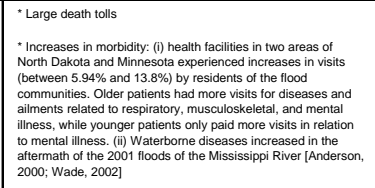 & 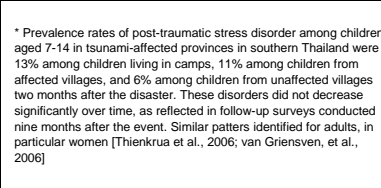 \\
\hline Raintall shocks & & 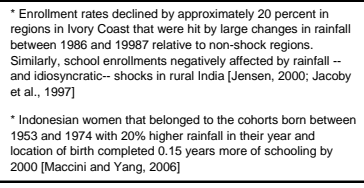 & 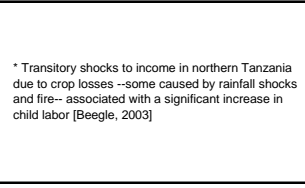 & 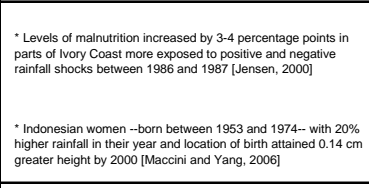 & 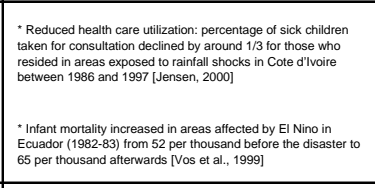 & \\
\hline Hurricanes & & 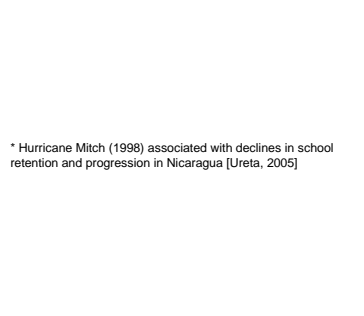 & 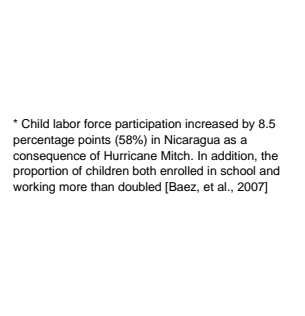 & 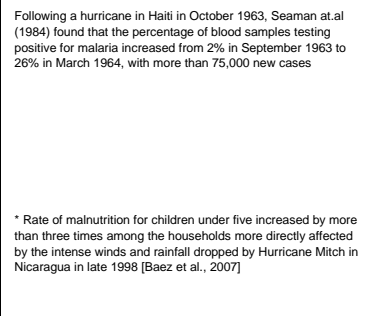 & 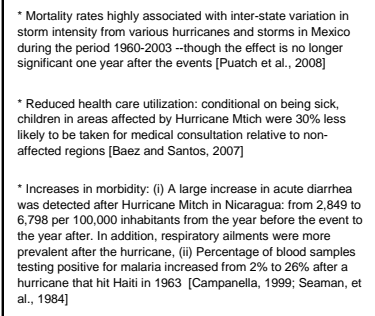 & 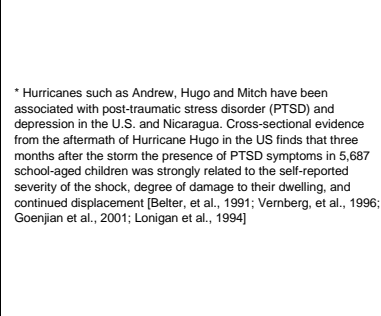 \\
\hline Earthquakes & 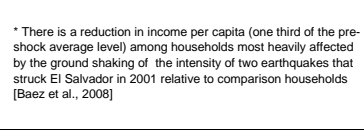 & & 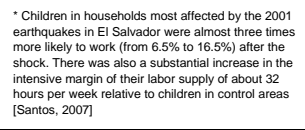 & & 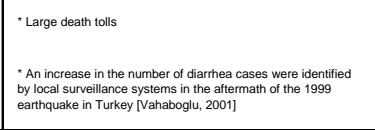 & 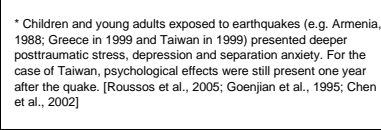 \\
\hline
\end{tabular}

